\title{
The seismic sequence of January-February 2014 at Cephalonia Island (Greece): constraints from SAR interferometry and GPS
}

\author{
P. Briole, ${ }^{1}$ P. Elias, ${ }^{2}$ I. Parcharidis,${ }^{3}$ C. Bignami, ${ }^{4}$ G. Benekos, ${ }^{3}$ S. Samsonov, ${ }^{5}$ \\ C. Kyriakopoulos, ${ }^{6}$ S. Stramondo, ${ }^{4}$ N. Chamot-Rooke, ${ }^{1}$ M.L. Drakatou ${ }^{3,4}$ \\ and G. Drakatos ${ }^{2}$ \\ ${ }^{1}$ Ecole Normale Supérieure, Laboratoire de Géologie - UMR CNRS 8538, Paris, France.E-mail: pierre.briole@ens.fr \\ ${ }^{2}$ National Observatory of Athens, Greece \\ ${ }^{3}$ Department of Geography, Harokopio University of Athens, Athens, Greece \\ ${ }^{4}$ Istituto Nazionale di Geofisica e Vulcanologia, Rome, Italy \\ ${ }^{5}$ Canada Centre for Mapping and Earth Observation, Natural Resources Canada, Ottawa, Canada \\ ${ }^{6}$ Department of Earth Sciences, University of California, Riverside, CA, USA
}

Accepted 2015 August 20. Received 2015 August 3; in original form 2014 November 21

\begin{abstract}
S UMMAR Y
We analysed the ground deformation produced by the $M_{\mathrm{w}}=6.12014$ January 26 and $M_{\mathrm{w}}=$ 6.0 2014 February 3 Cephalonia earthquakes, western Greece. Campaign GPS measurements and RADARSAT-2 synthetic aperture radar (SAR) interferometry provide constraints on the overall deformation produced by the sequence. TerraSAR-X and COSMO-SkyMed SAR interferometry provide constraints on the second earthquake separately. Two permanent GPS stations captured the two coseismic offsets and show no pre- or post-seismic transients. Most of the deformation is concentrated in the Paliki peninsula which is consistent with the location of the seismicity and the damages. Both GPS and SAR interferometry indicate areas with large deformation gradients probably due to shallow effects. Given the limitations on the data and on the knowledge of the structure and rheology of the crust, we used a simple elastic model to fit the ground displacements. Although such model cannot fit all the detail of the deformation, it is expected to provide a robust estimate of the overall geometry and slip of the fault. The good data coverage in azimuth and distance contributes to the robustness of the model. The entire sequence is modelled with a strike slip fault dipping $70^{\circ}$ east and cutting most of the brittle crust beneath Paliki, with an upper edge located at $2.5 \mathrm{~km}$ depth and a deeper edge at $8.5 \mathrm{~km}$. This fault is oriented $\mathrm{N} 14^{\circ}$ which corresponds to the azimuth of the Cephalonia Transform Fault (CTF). The fit to the data is significantly improved by adding a secondary shallow strike-slip fault with low dip angle $\left(30^{\circ}\right)$ with a component of reverse faulting on that shallow fault. The modelling of the February 3 event indicates that the faulting is shallow in the north of Paliki, with a centroid depth of $\sim 3.2 \mathrm{~km}$. The fit is improved when a single planar fault is replaced by a bent fault dipping $\sim 30^{\circ}$ in the uppermost $2 \mathrm{~km}$ and $\sim 70^{\circ}$ below. The fault of the January 26 earthquake, inferred from the difference between the two above models, is located south and beneath the February 3 fault, with a centroid depth of $\sim 6.4 \mathrm{~km}$. We interpret the 2014 fault zone as an east segment of the CTF located $\sim 7 \mathrm{~km}$ east of the main axis of the CTF, which location is constrained by the elastic modelling of the interseismic GPS velocities. The aftershock sequence is mostly located between the January 26 fault and the axis of the CTF. According to our analysis, the Paliki peninsula is partly dragged north with the Apulian platform with $\sim 7 \mathrm{~mm} \mathrm{yr}^{-1}$ of shear accommodated offshore to the west. During the last $30 \mathrm{yr}$ three main sequences occurred along the CTF, in 1983, 2003 and 2014 breaking a large part of the fault, with a gap of 20-40 km left between Cephalonia and Lefkada.
\end{abstract}

Key words: Radar interferometry; Earthquake dynamics; Dynamics: seismotectonics; Europe. 


\section{INTRODUCTION}

On 2014 January 26 and February 3, two earthquakes of magnitude $M_{\mathrm{w}}=6.1$ and 6.0 occurred at shallow depth beneath Cephalonia (Fig. 1; Table 1), producing extensive damages in the western part of the island (EPPO/ITSAK 2014; Nikolaou et al. 2014; Valkaniotis et al. 2014). Those earthquakes awakened the memory of the disastrous earthquake of 1953 and the most recent 2003 and 1983 earthquakes, respectively in Lefkada and south of Cephalonia.

Being regularly subjected to strong earthquakes, exceeding $M=6$, the island of Cephalonia, western Greece (Fig. 1), has long attracted the attention of seismologists and earthquake engineers (e.g. Papagiannopoulos et al. 2012). Cephalonia represents one of the most external zones of the Hellenides, together with the nearby Paxos and Zakinthos islands (e.g. Aubouin \& Dercourt 1962). Most of the Cephalonia rocks (Fig. 2) consist in pre-Apulian series, except to the east where Ionian series were thrusted westward during the Alpine orogeny (Lekkas et al. 2001). The core of the island is made of the thick Cretaceous brecciated limestones, while to the west Miocene marls and flyschs cover Eocene limestones in the

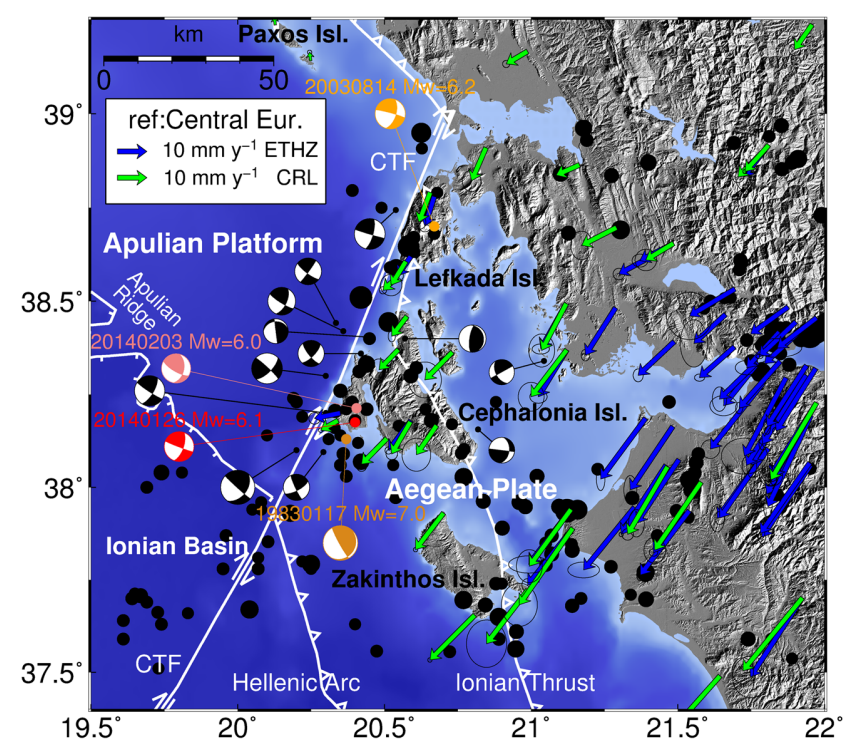

Figure 1. The central Ionian islands with, in black and white, the focal mechanisms of $M>5$ earthquakes around Cephalonia between 1972 and 2014 (from Kokinou et al. 2006) and the $M_{\mathrm{L}}>3.5$ seismicity from the National Observatory of Athens (NOA) catalogue for the period 2009-2013 (black circles). The G-CMT focal mechanisms of the earthquakes of 2014 January 26 and February 3 are plotted in colour, as well as those of 2003 August 14 and 1983 January 17. The vectors represent the GPS velocities with respect to stable Europe, in green from the field campaigns of the Eidgenössische Technische Hochschule Zürich (ETHZ; Müller 2011) and in blue from the campaigns of the Corinth Rift Laboratory (CRL, http://crlab.eu).

Table 1. Focal mechanism of the 2014 January 26 and February 3 earthquakes from the Global CMT (G-CMT) and from other sources for February 3.

\begin{tabular}{lccccc}
\hline Event & Centre & $\begin{array}{c}\text { Strike } \\
\left({ }^{\circ}\right)\end{array}$ & $\begin{array}{c}\text { Dip } \\
\left({ }^{\circ}\right)\end{array}$ & $\begin{array}{c}\text { Rake } \\
\left({ }^{\circ}\right)\end{array}$ & $\begin{array}{c}\text { Moment } \\
\left(\times 10^{18} \mathrm{~N} \mathrm{~m}\right)\end{array}$ \\
\hline 26 January & G-CMT & 20 & 65 & 177 & 2.08 \\
\hline 3 February & G-CMT & 12 & 45 & 154 & 1.49 \\
& NOA & 13 & 75 & 163 & 1.02 \\
& AUTH & 17 & 87 & 177 & 0.96 \\
& INGV (quick) & 13 & 43 & 161 & 2.00 \\
\hline
\end{tabular}

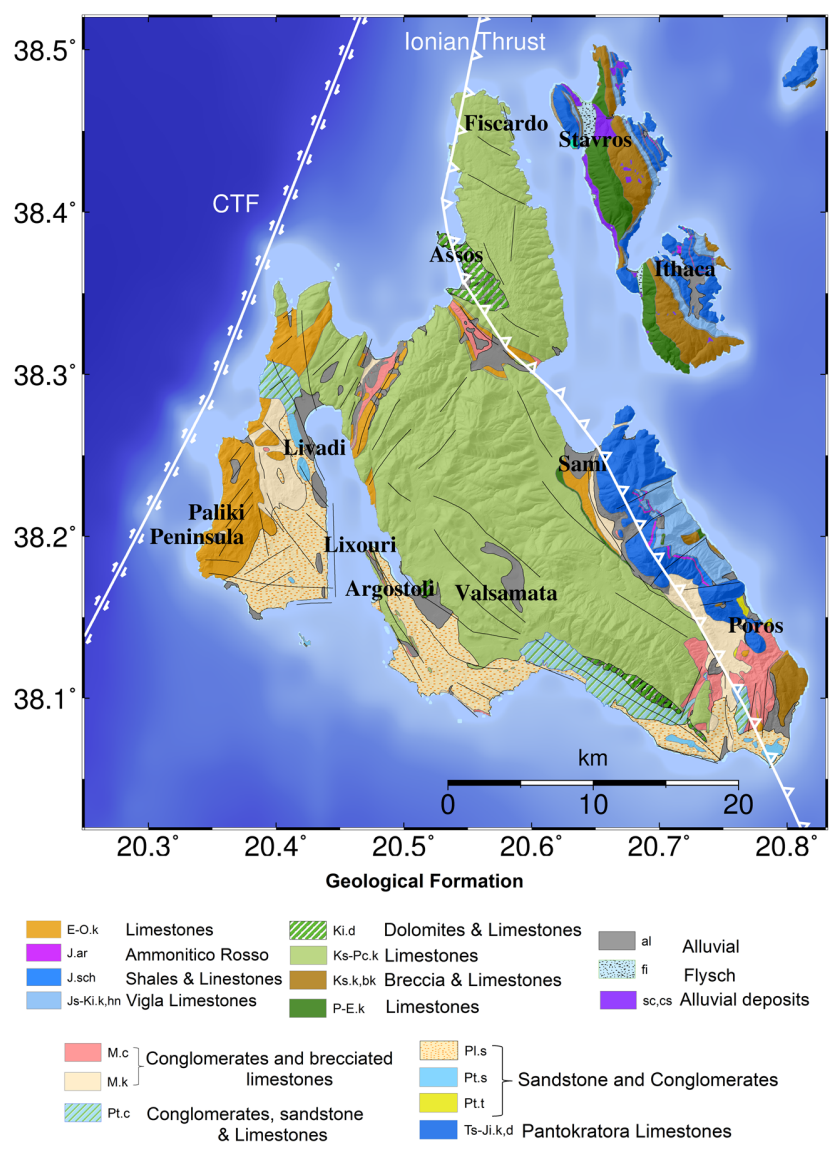

Figure 2. Geological map of Cephalonia (polygons are courtesy of Institute of Geology \& Mineral Exploration) with the locations names used in the paper. The fault traces were digitized from Lagios et al. (2012).

Paliki Peninsula. The thickness of the deep units on the island itself remains unknown, but it is generally accepted that the pre-Apulian series, from Trias to Cretaceous, may be 4-5 km thick. Younger series may be only several hundred metres thick. There are several inferred shallow faults in the island exhibiting and accommodating an overall shortening regime (Lekkas et al. 2001; Lagios et al. 2012).

Kokinou et al. (2006) analysed the seismicity of the area, gathering focal mechanisms of $M>5$ earthquakes that occurred between 1972 and 2003 (Fig. 1). The major event of 1983 January 17 $\left(M_{\mathrm{s}}=7.0\right)$ and its aftershocks were studied by several authors (e.g. Scordilis et al. 1985; Kiratzi \& Langston 1991). The strike slip earthquakes hitting the western part of Cephalonia mark one of the major structural discontinuities of the eastern Mediterranean: the 'Cephalonia Transform Fault' (CTF; Sorel 1989; Hatzfeld et al. 1995; Le Pichon et al. 1995; Louvari et al. 1999; Clement et al. 2000; Sachpazi et al. 2000; Shaw \& Jackson 2010; Papoulia et al. 2014). This fault zone, located at the northwest termination of the Hellenic Arc, separates the Apulian microplate and the Hellenic foreland with a shear velocity on the order of $20 \mathrm{~mm} \mathrm{yr}^{-1}$ (Floyd et al. 2010; Pérouse et al. 2012). Right lateral strike slip events dominate to the west and the presence of reverse faulting earthquakes in the north and east of the island. The $M_{\mathrm{s}}=7.2$ earthquake of 1953 (Stiros et al. 1994) and the $M_{\mathrm{s}}=5.8$ of 1992 (Tselentis et al. 1997) are likely to belong to the latter family, the $M_{\mathrm{s}}=6.3$ of 1972 (Papadimitriou 1993), the $M_{\mathrm{s}}=7.0$ of 1983 


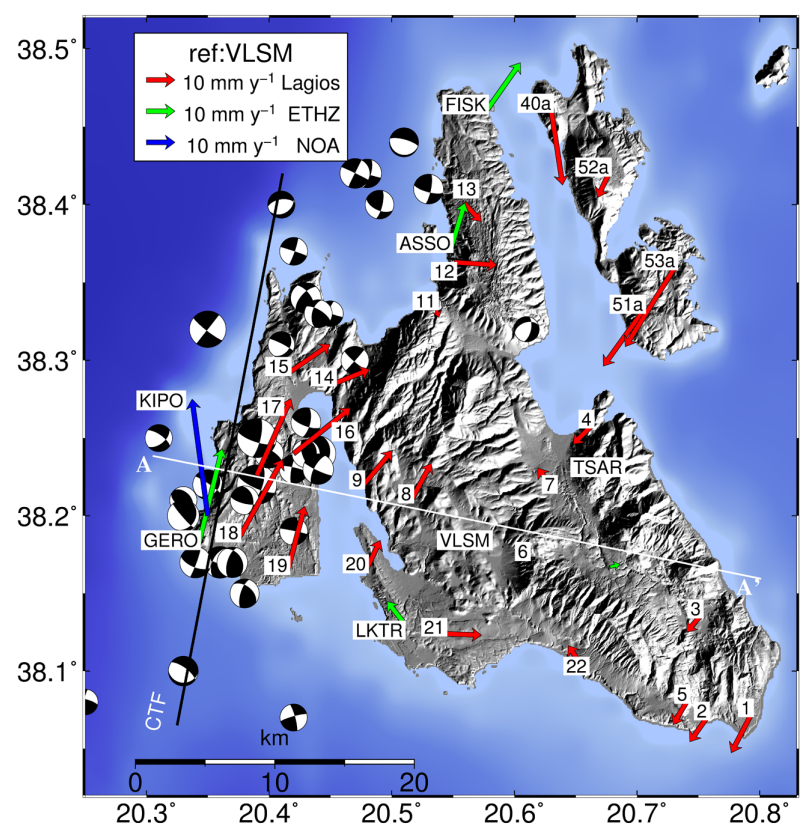

Figure 3. Focal mechanisms determined by the NOA for the period 20062013. More than half one of their fault planes with azimuth $15 \pm 5^{\circ}$, thus closely aligned with the CTF. The location of the CTF plotted here is inferred from our analysis of the interseismic GPS vectors. GPS velocities (with respect to VLSM) of GPS points located at Cephalonia: in green from Müller (2011), in red from Lagios et al. (2012), and in blue our solution for the KIPO station belonging to the NOA network (Ganas et al. 2013). Values are in Table 3. The shortening rate in the $\mathrm{N} 102^{\circ}$ azimuth (along the $\mathrm{A}-\mathrm{A}^{\prime}$ line perpendicular to the CTF) is $0.05 \mu$ strain $\mathrm{yr}^{-1}$.
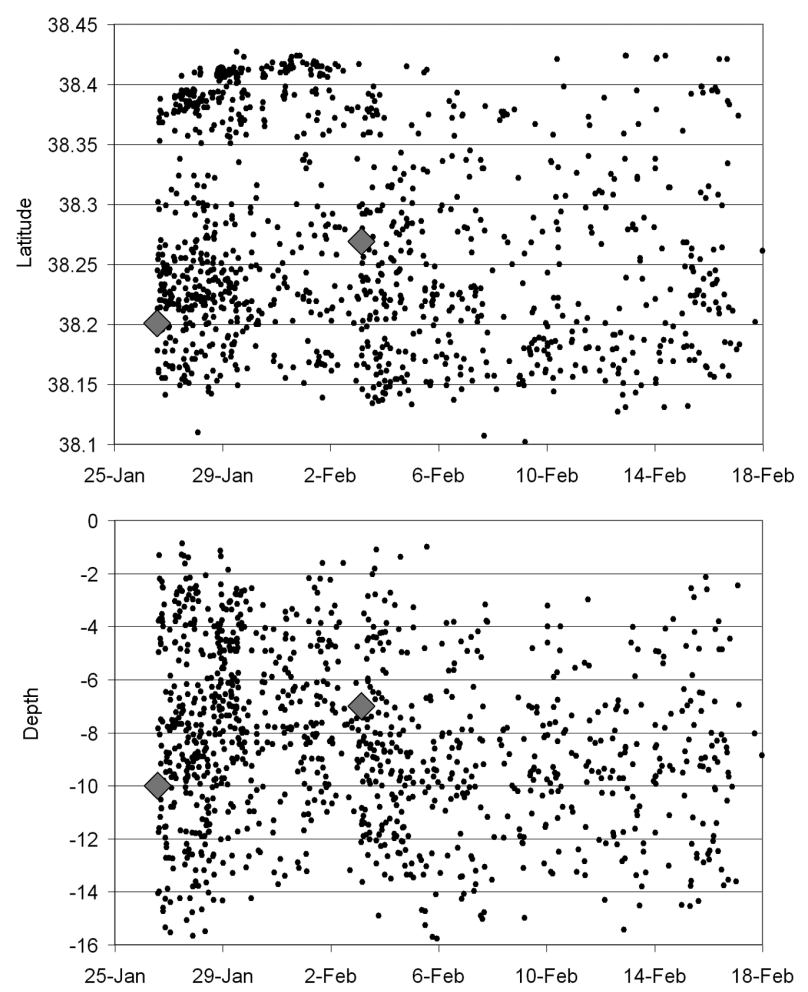

Figure 4. Temporal evolution of the seismicity as a function of latitude and depth (from Karakostas et al. 2015). The grey diamonds correspond to the main events of February 26 and January 3.
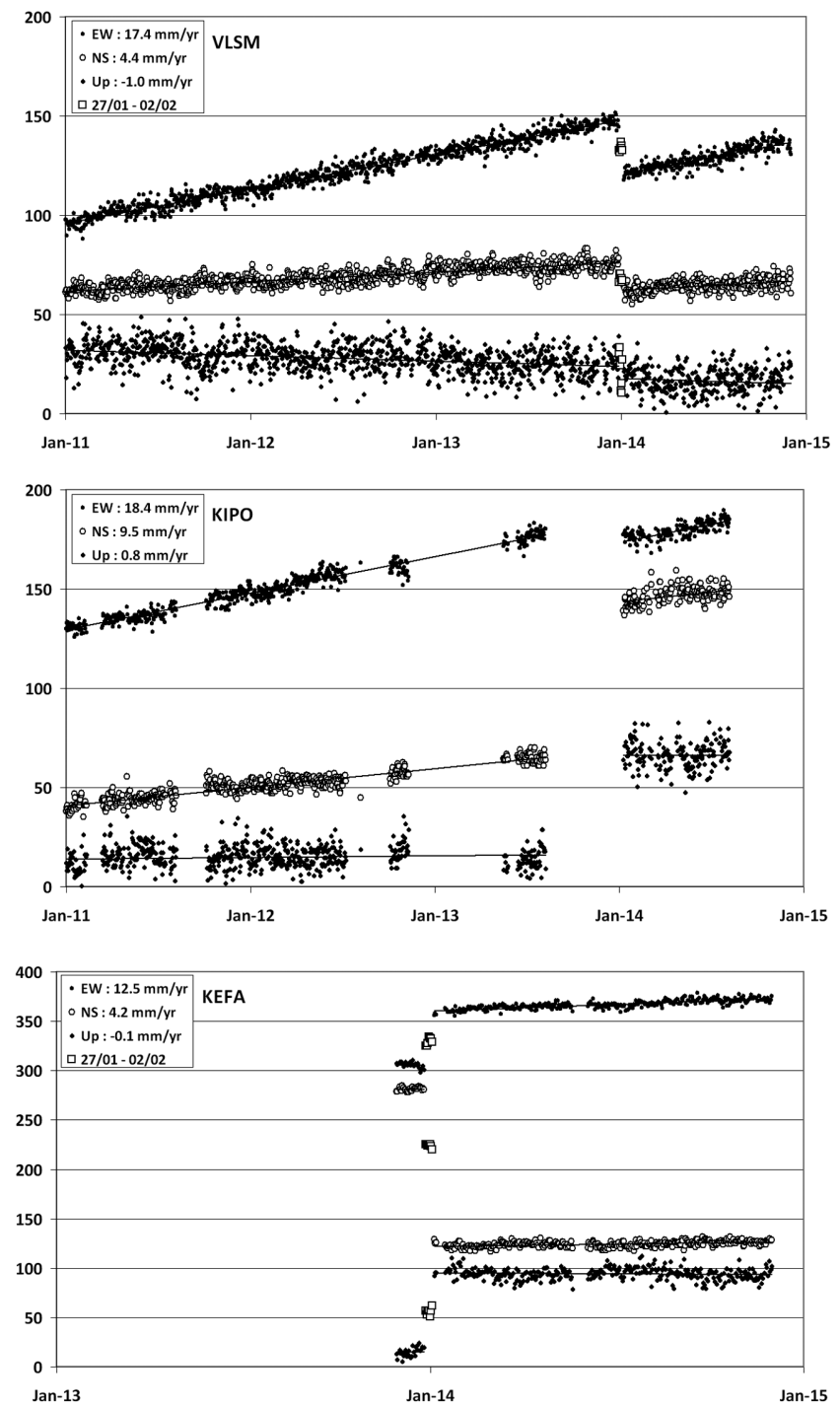

Figure 5. Time-series of the permanent GNSS stations VLSM, KIPO and KEFA. The vertical scale is in millimetres. The open squares in the VLSM and KEFA time-series correspond to the coordinates in the interval between the two main shocks. The values of the coseismic offsets are in Table 2.

(Scordilis et al. 1985) and those of 2014 to the former. The seismic crises are often composed of several major events, with the strongest not always being the first as this was the case in 1953. Such occurrence of temporally clustered earthquakes is not rare and there are several examples elsewhere in Greece (e.g. Migdonian basin, 1978; eastern Corinth gulf, 1981). Models of stress transfer in the crust are often proposed to explain those cascades of events (e.g. Papadimitriou 2002).

Fig. 3 shows the GPS velocities at Cephalonia and Ithaca published by Müller (2011) and Lagios et al. (2012). The vectors in the Paliki peninsula differ from the others in Cephalonia and show relative velocities on the order of $10 \mathrm{~mm} \mathrm{yr}^{-1}$ between the west of the peninsula and the main island. The internal deformation of Cephalonia observed by GPS since $15 \mathrm{yr}$ is presented and discussed in detail by Lagios et al. (2012). In the next section, we use those GPS vectors to constrain the parameters of the locked fault model fitting the observed strain accumulation before the 2014 earthquake.

Fig. 4 shows the temporal distribution in latitude and depth of 1113 relocated aftershocks (Karakostas et al. 2015) for the period 2014 January 26 to February 22. The rupture area we 
Table 2. Observed and modelled coseismic displacements. Observed displacements are from our study for the CGPS points and from Sakkas \& Lagios (2015) slightly shifted to fit with our observed offset at VLSM. For VLSM and KEFA there is a determination for each earthquake. The parameters of the model are in Table 5. The average scatter between observations and model (removing outliers 15 and 14) is $16 \mathrm{~mm}$ in east, $23 \mathrm{~mm}$ in north and $23 \mathrm{~mm}$ in vertical.

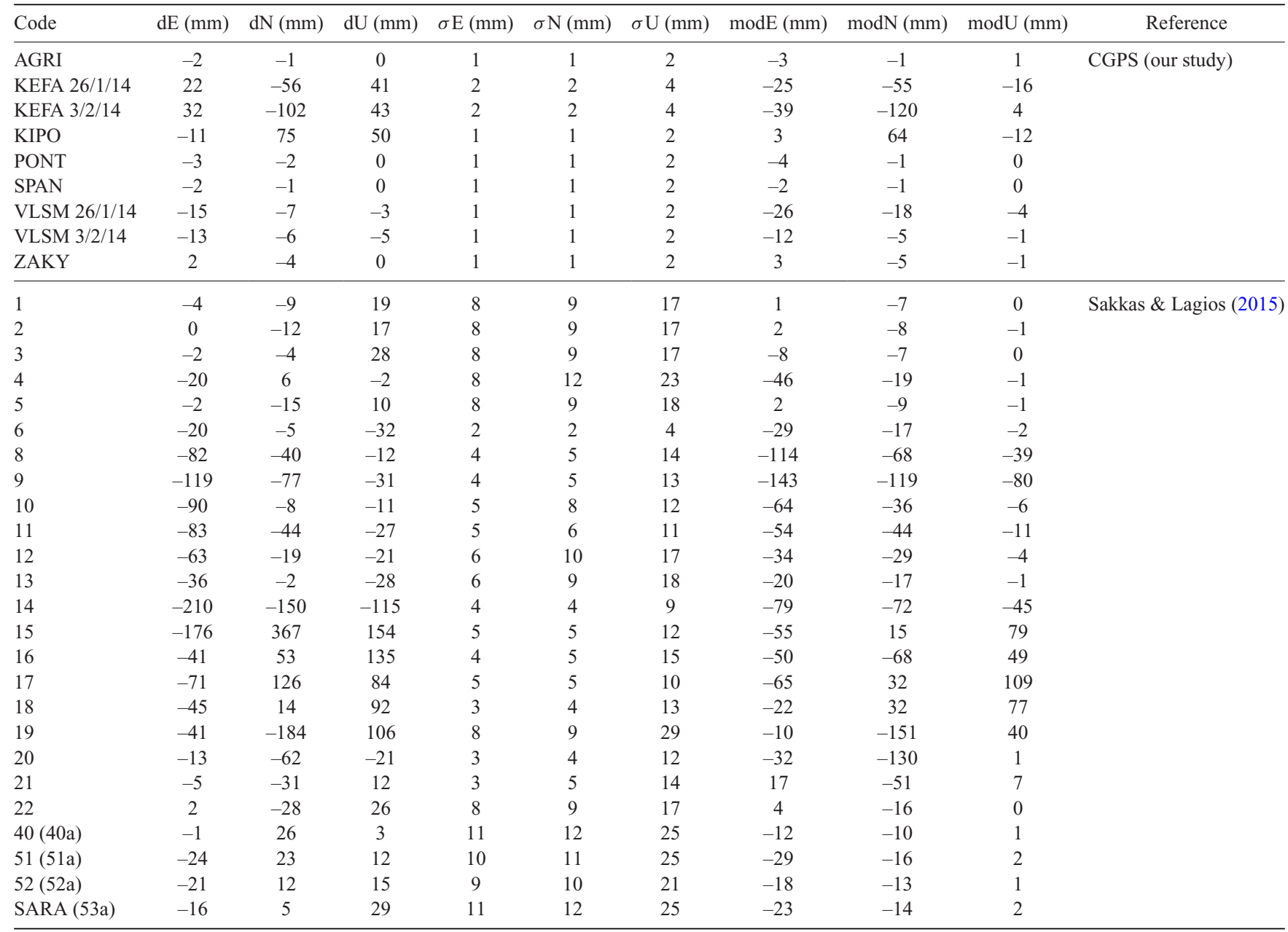

infer from our data analysis below fits well with the location of the seismicity.

\section{GPS COSEISMIC AND INTERSEISMIC DATA}

Using the GIPSY-OASIS v6.12 software, we processed the data acquired at three permanent GNSS stations located in Cephalonia (VLSM, KIPO and KEFA) and four around (ZAKY, PONT and SPAN AGRI). Fig. 5 shows the time-series of the three stations of Cephalonia. The coseismic offset produced by the two main earthquakes can be accurately measured at VLSM and KEFA but not at KIPO which was not working at the time of the earthquakes. We can see that there is no visible pre- or post-seismic transient recorded at those permanent stations. We used in our models the coseismic campaign data of Sakkas \& Lagios (2015). The values of the coseismic offsets are listed in Table 2. We applied a slight offset to align their vectors on our solution at VLSM.

We used also the interseismic GPS data (Müller 2011; Lagios et al. 2012; Table 3) to estimate the location of a best-fitting locked fault (and the related parameters, that is values of locking depth and CTF velocity) during the documented period of strain accumulation preceding the 2014 sequence. To perform this estimation accurately, we placed a constraint on the velocity of the Apulian platform, which constitute the western side of the CTF, by introducing a virtual point on that platform with a velocity equal to the average velocity of the Apulian platform as determined by Ventura et al. 2014 (i.e. $v_{\mathrm{E}}$ $=23.6 \mathrm{~mm} \mathrm{yr}^{-1}$ and $v_{\mathrm{N}}=18.9 \mathrm{~mm} \mathrm{yr}^{-1}$ in the ITRF2008), and assuming that the platform is rigid, considering in particular the low level of seismicity there. We assigned to that virtual point a large velocity uncertainty $\left(1.5 \mathrm{~mm} \mathrm{yr}^{-1}\right)$ so as to take into account the uncertainty on the behaviour of the platform and not weighting too much in our inversions.

We used the vectors (26) from all points located south of point 11. Vectors from Ithaca and from the points located north of 11 were not used.

Assuming that the interseismic deformation is due to an elastic loading of the upper crust by a steadily creeping fault at depth, and assuming infinite length and depth, vertical fault beneath the locking depth, and pure strike-slip relative motion, the best fit to the vectors is obtained with a fault passing at $20.37^{\circ} \mathrm{E}, 38.22^{\circ} \mathrm{N}$, with azimuth $12^{\circ}$, locking depth $11.5 \mathrm{~km}$ and shear velocity $19.5 \mathrm{~mm}$ $\mathrm{yr}^{-1}$. Fig. 6 shows the projection of the vectors along the line $\mathrm{A}-\mathrm{A}^{\prime}$ and the best-fitting solution. Fig. 7 shows the best-fitting values of locking depth and CTF velocity and the mean residual when testing different locations of the $\mathrm{CTF}$ along the $\mathrm{A}-\mathrm{A}^{\prime}$ axis. The best fit (mean residual of $1.14 \mathrm{~mm} \mathrm{yr}^{-1}$ ) is obtained for a CTF located at $20.37^{\circ} \pm 2 \mathrm{~km}$ (at the latitude $38.22^{\circ}$ ). In that range, the locking 
Table 3. Interseismic velocity field of GPS points located at Cephalonia and around. Stars indicate continuous GPS stations. The velocities are absolute velocities in the ITRF2008. The values of Müller (2011) and Lagios et al. (2012) are very slightly shifted from those given in the corresponding publications, as we used our determination of the velocity of VLSM, and shifted the others to align the three data sets.

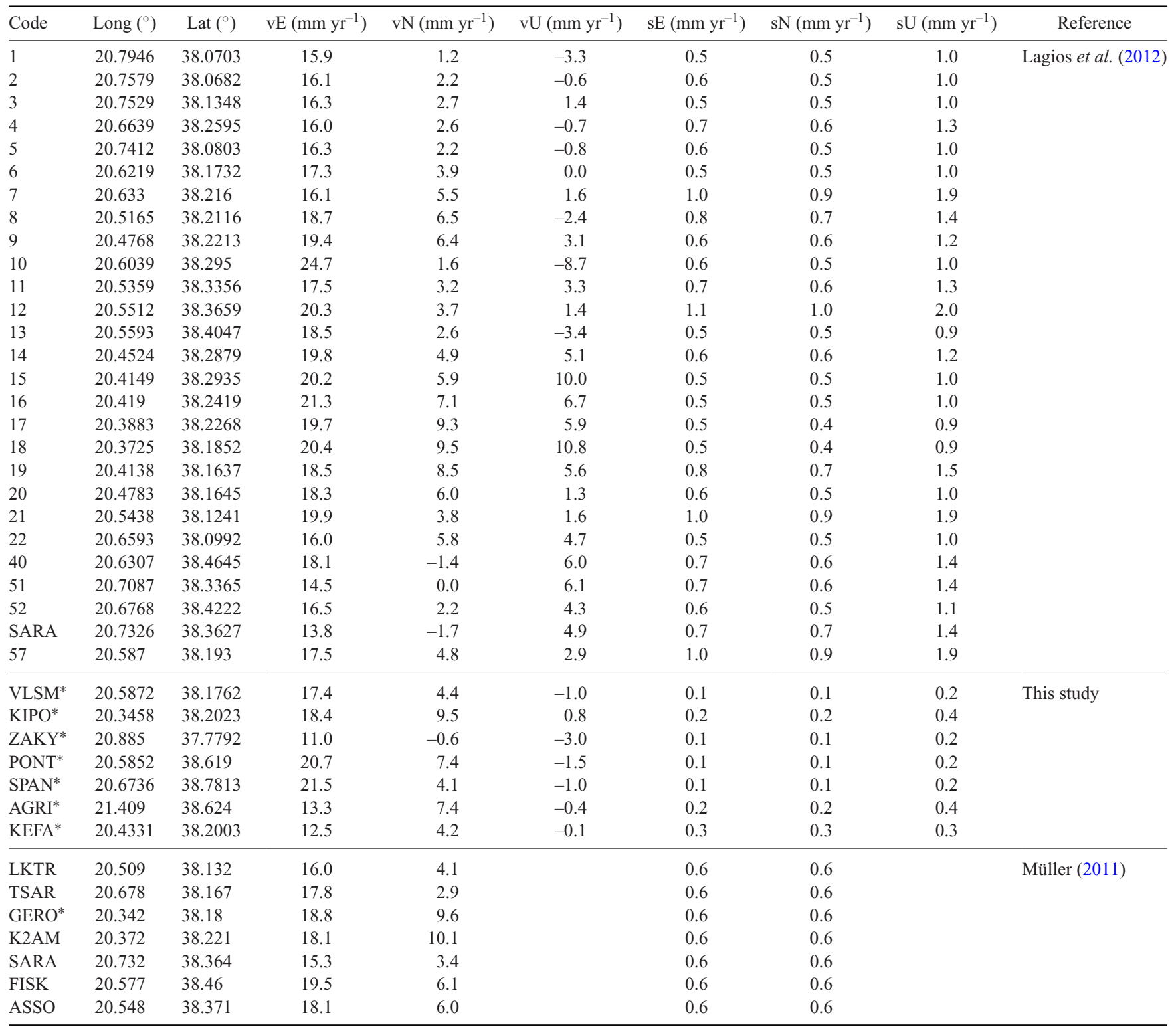

depth is stable at a value of $11.5-12 \mathrm{~km}$ and the CTF velocity is in the range $18.5-19.5 \mathrm{~mm} \mathrm{yr}^{-1}$ which is around the highest possible velocity considering the global velocity field of the area according to Pérouse et al. 2012. Fig. 8 shows that the fit slightly improves when the locking depth increases, but at the same time the CTF velocity increases and if we consider a highest possible value of $20 \mathrm{~mm} \mathrm{yr}^{-1}$, then the locking depth should not exceed $12 \mathrm{~km}$.

Our best-fitting locking depth of $11.5 \mathrm{~km}$ is consistent with that of the seismicity during the aftershocks sequence, however Fig. 8 shows that lower values of the locking depth, until $\sim 8 \mathrm{~km}$ are possible (until an mean residual of $\sim 1.3 \mathrm{~mm} \mathrm{yr}^{-1}$, which corresponds to a range of variation of the CTF longitude of $\pm 2 \mathrm{~km}$ according to Fig. 7), and those values would be associated with lower values of the CFT velocity $\left(\sim 18 \mathrm{~mm} \mathrm{yr}^{-1}\right)$.

The vectors indicate also a shortening of $\sim 0.05 \mu$ strain $\mathrm{yr}^{-1}$ in the $\mathrm{N} 102^{\circ} \mathrm{E}$ direction (line $\mathrm{A}-\mathrm{A}^{\prime}$ in Fig. 3) across the island. Two points in the north of Paliki, 14 and 15, show a significantly different behaviour and we will see later that they are also discordant in the coseismic vectors. All the above inversions were performed with and without introducing the points 14 and 15 and we noticed that there was no significant impact on the results, which is a proof of the stability of the above calculations.

\section{SAR INTERFEROMETRY}

Interferograms from SAR images acquired by TerraSAR-X (TSX), COSMO-SkyMed (CSK), and RADARSAT-2 (RS2; Table 4) were computed with GAMMA software (Wegmuller \& Werner 1997). While the CSK and TSX interferograms captured only the February 3 earthquake, the RS 2 interferogram captured also the January 26 one. For TSX and CSK the topographic phase was removed using a high resolution $(\sim 5 \mathrm{~m})$ digital elevation model (DEM) derived from airborne photogrammetry, with vertical accuracy better than $5 \mathrm{~m}$. For RS2 we used a $\sim 30 \mathrm{~m}$ resolution ASTER DEM 


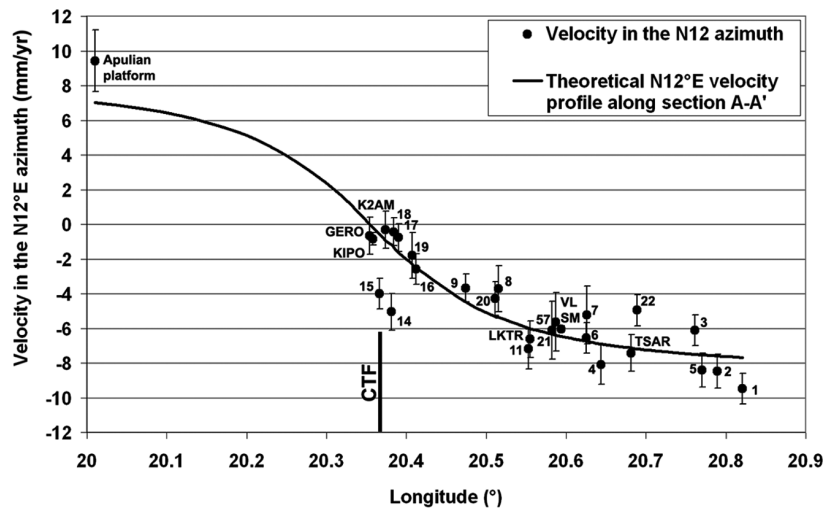

Figure 6. Best-fitting solution for the interseismic locking depth calculated using an elastic model and constrained by the GPS velocities at 26 GPS points of Cephalonia (from Müller 2011, Lagios et al. 2012, and our processing for KIPO and VLSM) projected to the $\mathrm{N} 12^{\circ} \mathrm{E}$ direction (section $\mathrm{A}-\mathrm{A}^{\prime}$, Fig. 3) and a virtual point simulating the velocity of the Apulian platform west of Cephalonia (from the vectors of Ventura et al. 2014 and assuming the platform rigid off-shore). The best-fitting locking depth and long-term slip are $11.5 \mathrm{~km}$ and $19.5 \mathrm{~mm} \mathrm{yr}^{-1}$. Location of the CTF inferred from our study: longitude $20.37^{\circ}$ at the latitude $38.22^{\circ}$, azimuth $12^{\circ}$.

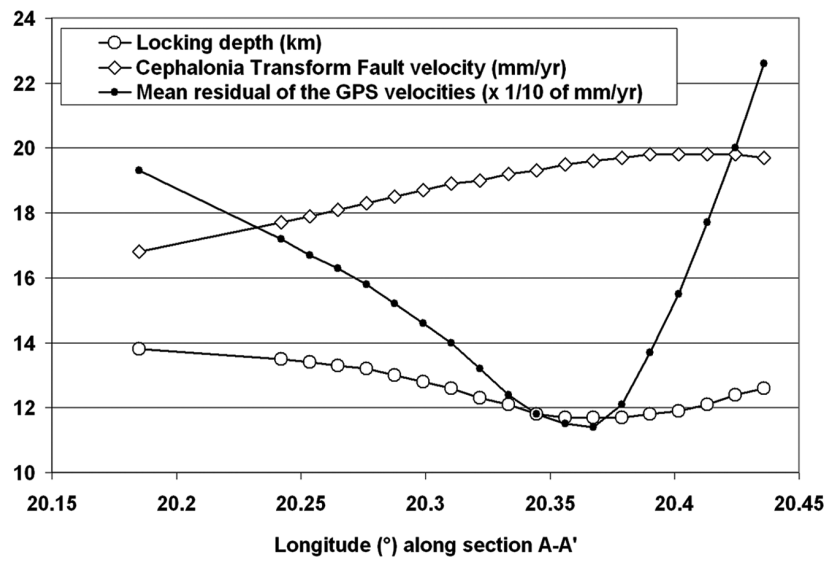

Figure 7. Fit of the GPS velocities as a function of the assigned location of the CTF along the $\mathrm{A}-\mathrm{A}^{\prime}$ section. The best fit (mean residual of 1.14 $\mathrm{mm} \mathrm{yr}^{-1}$ ) is obtained for a CTF located at $20.37^{\circ}$ (at the latitude $38.22^{\circ}$ ). The best-fitting values of locking depth and CTF velocity are plotted, they are in the range $18.5-19.5 \mathrm{~mm} \mathrm{yr}^{-1}$ for the velocity and stable around 12 $\mathrm{km}$ for the locking depth.

(http://gdex.cr.usgs.gov/gdex/). The flattened interferograms were filtered using an adaptive noise filter (Goldstein \& Werner 1998) with a small window size and unwrapped by means of Minimum Cost Flow (MCF) algorithm (Costantini 1998) using the qualitative coherence (above 0.3 ) as a weight for the MCF solution. A baseline refinement was applied for removing residual phase ramps.

The RS2 interferogram (Fig. 9) was computed from two ascending SAR acquisitions of 2011 December 12 and 2014 February 11 (perpendicular baseline $55 \mathrm{~m}$ ). The Wide Fine beam with a spatial coverage of $170 \times 150 \mathrm{~km}$ and a spatial resolution of $5 \times 7$ $\mathrm{m}$ was used. The multilooked factor applied to the interferogram was $3 \times 5$, which resulted in a ground resolution of $14 \times 26 \mathrm{~m}$. Due to a large temporal baseline (over $2 \mathrm{yr}$ ) the interferometric coherence is low and spatially variable (patchy). There is a relatively good coherence over the coastal areas of Paliki peninsula, where coseismic fringes are clearly observed. Maximum LOS motion reaches $\sim 12 \mathrm{~cm}$ along both directions (towards and away from the satellite).

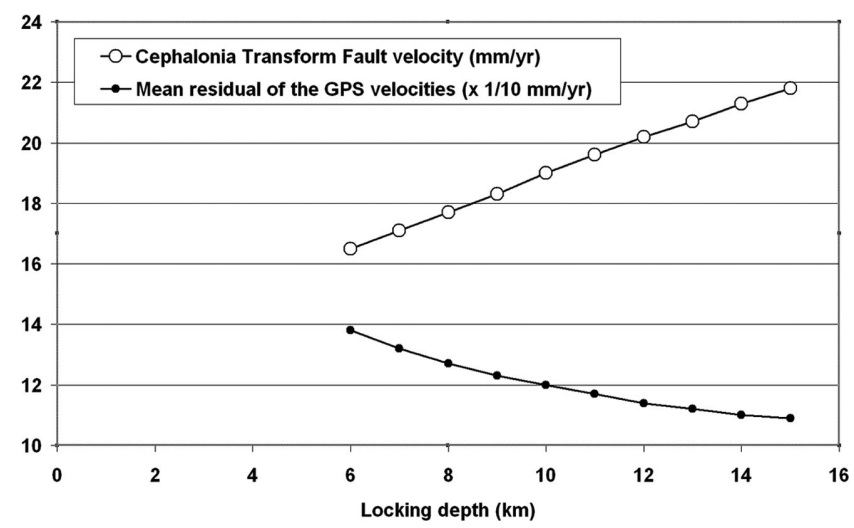

Figure 8. Fit of the GPS velocities as a function of the assigned locking depth. The fit improves when the locking depth increases. However, the CTF velocity also increases with the locking depth and if we consider that it cannot be larger than $20 \mathrm{~mm} \mathrm{yr}^{-1}$, then the locking depth should not exceed $12 \mathrm{~km}$.

The TSX data we used are in the strip map high resolution mode allowing to measure wide areas with a spatial resolution of $\sim 3 \mathrm{~m}$. We produced an interferogram spanning eleven days from 2014 January 28 until February 8 (perpendicular baseline $108 \mathrm{~m}$ ), sampling the coseismic ground displacements of the February 3 event in the ascending geometry. The multi-look factor applied $(5 \times 5)$ corresponds to pixels of $\sim 15 \times 15 \mathrm{~m}$ on the ground. The interferogram (Fig. 10) exhibits a maximum motion of $\sim 10 \mathrm{~cm}$ along the satellite line of sight (LOS) towards the satellite sensor, in the centre-south of Paliki Peninsula and a maximum LOS motion of $\sim 7 \mathrm{~cm}$ away from the satellite in the north and east of the peninsula.

The CSK interferogram (Fig. 11) was computed from a pair of descending SAR acquisitions of 2014 February 2 and February 10 (perpendicular baseline $319 \mathrm{~m}$ ). The multilook factor applied $(3 \times 3)$ corresponds to $\sim 6 \times 6 \mathrm{~m}$ pixel size on the ground. The deformed area is generally the same as with TSX data, but the pattern and amount of LOS motion differ because of the different view point. A maximum LOS motion of $\sim 8 \mathrm{~cm}$ toward the satellite is observed in the Paliki peninsula, while a maximum LOS motion of $\sim 18 \mathrm{~cm}$ away from the satellite is measured in the northwestern Paliki peninsula, and also along the northeastern side of the Argostoli gulf. A second interferogram covering the period February 2 to February 18 with a smaller baseline $(124 \mathrm{~m})$ shows no significant differences but less coherence because of the longer time interval.

\section{FRINGES PICKING AND LOS DATA}

Various methods are available for extracting numerical data from interferograms for using in the modelling software. One method consists of unwrapping and smoothing the interferograms and then sampling LOS values on uniform or non-uniform grids. The use of this method implies that the interferograms can be unwrapped properly which was questionable in our case because of their low coherence in many areas of the scene. The approach we employed consisted of picking data directly from the fringes where they are clearly visible and not ambiguous. We picked 330 points for TSX, 920 for CSK which is the most coherent of the three interferograms and 115 for RS2. The picked contours are reported in white over the interferograms in Figs 9-11.

A difficulty with SAR interferograms is to define their zero value. For this purpose, we used the conjunction between the coseismic offsets at VLSM and KIPO and the fringes in the vicinity of those 
Table 4. Characteristics of the three differential interferograms used in this study.

\begin{tabular}{lccccccccc}
\hline Sens. & Passing direction & Incid. angle $\left(^{\circ}\right)$ & Master date & Slave date & Span $(\mathrm{d})$ & $\mathrm{B}_{\text {perp }}(\mathrm{m})$ & Resol. Rg/Az $(\mathrm{m})$ & Mult. factor rg/az & Imaging mode \\
\hline TSX & Asc. & 21.6 & $28 / 1 / 14$ & $8 / 2 / 14$ & 11 & 108 & $3 \times 3$ & $5 \times 5$ \\
CSK & Desc. & 38.8 & $2 / 2 / 14$ & $10 / 2 / 14$ & 8 & 319 & $3 \times 3$ & $3 \times 3$ & Strip-map \\
RS2 & Asc. & 26.0 & $12 / 12 / 11$ & $11 / 2 / 14$ & 792 & 55 & $5 \times 7$ & h-image \\
\hline
\end{tabular}

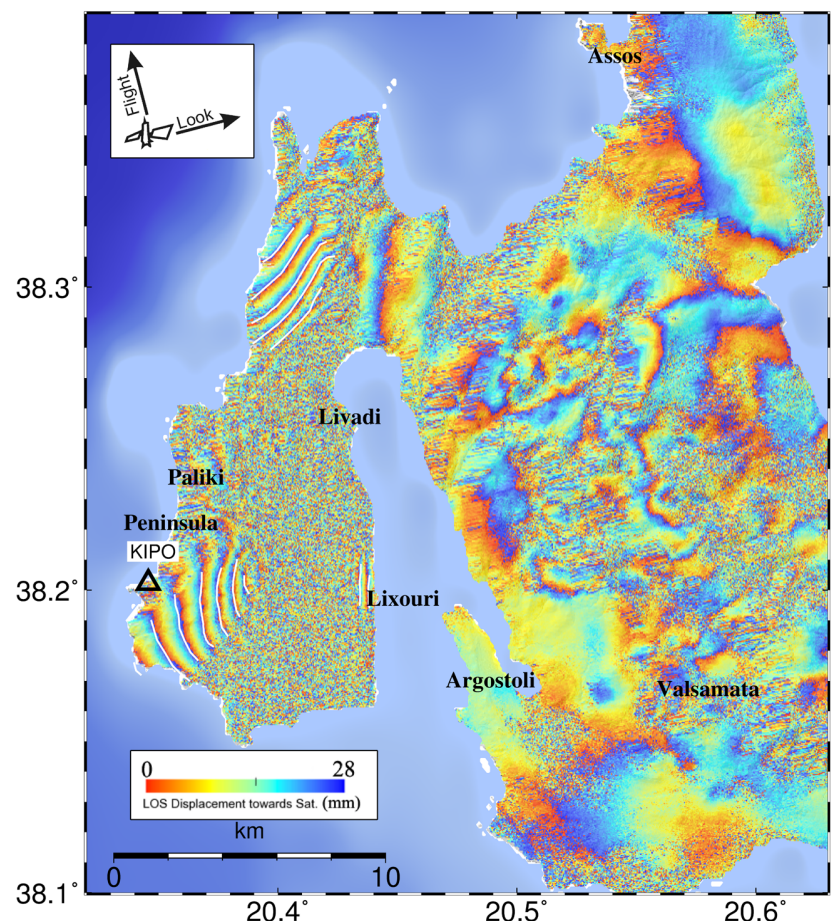

Figure 9. RS2 ascending interferogram for the period 2011 December $12-$ 2014 February 11. Perpendicular baseline: $55 \mathrm{~m}$. The satellite is passing west of the island, heading $\mathrm{N} 348^{\circ}$. The average incidence angle of the imagery is $26^{\circ}$. Line of sight vector (east, north, up): $-0.429,-0.09,0.899$. Blue corresponds to a motion towards the satellite. The white curves are the fringes that have been picked where they were visible in the wrapped interferogram (115 picked values). The origin of the fringes is deduced from the displacement of the GPS station KIPO.

stations. We tied first the coseismic GPS offset at VLSM projected along the CSK LOS $(-9 \mathrm{~mm})$ observed for the February 3 earthquake (see corresponding lines in Table 2) with the CSK fringes that have low noise around VLSM. This GPS site is located far from the faults area with a smooth deformation field, as shown by CSK, and it constitutes a reliable anchor for assessing the absolute LOS values of CSK (Fig. 11).

For RS2 (Fig. 9) we used the same method with the anchor at the GPS station KIPO for the cluster of fringes located close to that station. The coseismic offset at KIPO (Table 2) for the sequence of earthquakes corresponds to a line of sight change of $36 \mathrm{~mm}$. There are two other clusters of fringes in the RS2 data (one to the east, one to the north) for which we could not assess a connexion to the first one with better than one fringe uncertainty, therefore the uncertainty in the absolute LOS determination of those fringes is larger than one cycle (i.e. $28 \mathrm{~mm}$ ). As the RS2 interferogram samples a time window of $2 \mathrm{yr}$, a small amount of the observed deformation should result from the interseismic loading discussed previously, but according to the known interseismic strain rate in Paliki (Lagios et al. 2012) the signature of this loading, around $3 \mathrm{~mm}$, is small with respect to the coseismic signal.

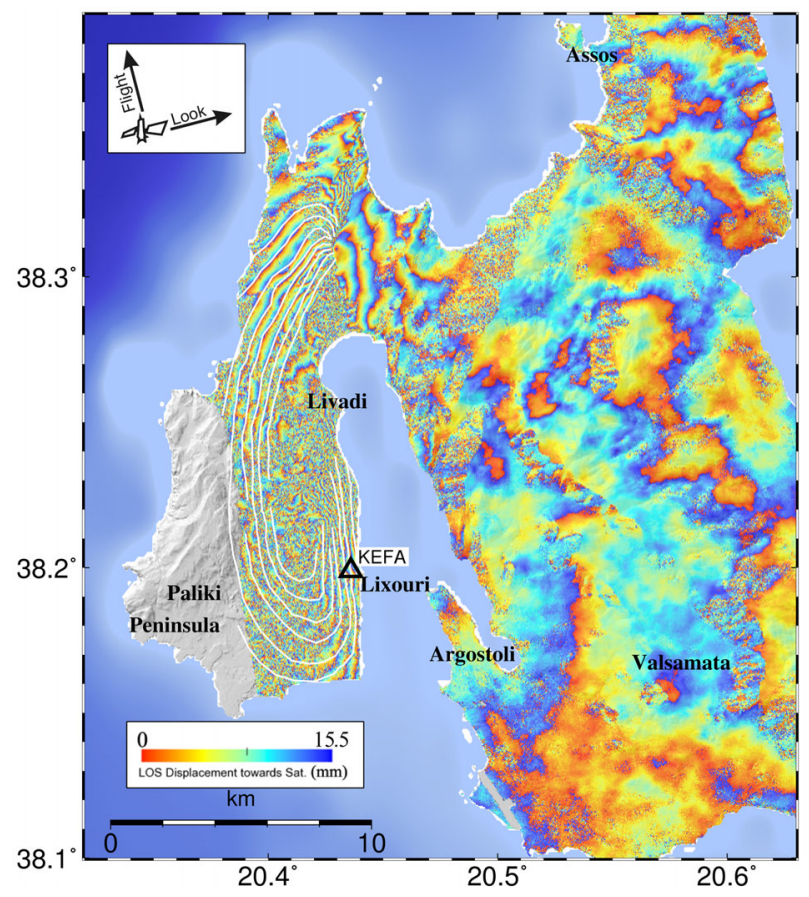

Figure 10. TSX ascending interferogram for the period 2014 January 28 February 8 . Perpendicular baseline: $108 \mathrm{~m}$. The satellite is passing west of the island, heading $\mathrm{N} 350^{\circ}$. The average incidence angle of the imagery is $21.6^{\circ}$. Line of sight vector (east, north, up): $-0.361,-0.070,0.930$. Blue corresponds to a motion towards the satellite. The white curves are the fringes that have been picked where they were visible in the wrapped interferogram (330 picked values). The coseismic displacement at the GPS station KEFA was used to anchor the TSX fringes.

For TSX (Fig. 10) we used as anchor the GPS station KEFA. As KEFA shows relatively large residuals in the further modelling of the data we cannot exclude a local effect, and if this effect would result from the station only and not the area, the tie would be biased. We therefore estimated the absolute accuracy of the TSX fringes picking to be not better than $\pm 15 \mathrm{~mm}$ in the LOS. Moreover we experienced difficulty connecting the south and north sectors of the TSX fringes in the west of Paliki, and we cannot exclude the possibility of one fringe cycle slip in the connexion of the northern sector of the TSX fringes.

Globally we estimated all picked and anchored points to have an absolute accuracy better than $\pm 30 \mathrm{~mm}$ and even less $( \pm 15 \mathrm{~mm})$ for the CSK data and for the TSX and RS2 data around KIPO. This level of accuracy is sufficient for the modelling presented in the next section because the number of sampled points is large with a good spatial coverage and because the main limitation arises from the hypothesis of homogenous and elasticity medium.

\section{MODELLING OF THE WHOLE SEQUENCE}

We use the formalism of Okada (1985) for forward modelling, assuming that the medium is a homogenous elastic half-space and 


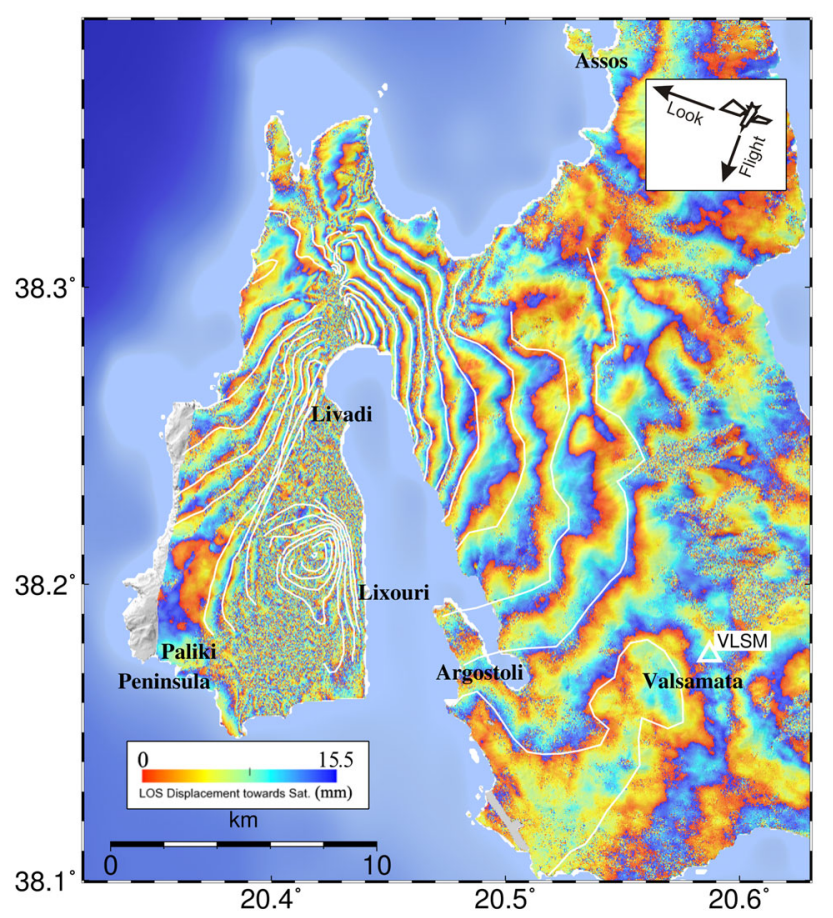

Figure 11. CSK descending interferogram for the period 2014 February $2-$ February 10. Perpendicular baseline: $319 \mathrm{~m}$. The satellite is passing east of the island, heading $\mathrm{N} 190^{\circ}$. The average incidence angle of the imagery is $38.8^{\circ}$. Line of sight vector (east, north, up): $0.617,-0.109,0.779$. Blue corresponds to a motion towards the satellite. The white curves are the fringes that have been picked where they were visible in the wrapped interferogram (920 picked values). The origin of the fringes is deduced from the displacement of the GPS station VLSM.

the faults rectangular with homogenous slip. Our inverse algorithm uses the Tarantola \& Valette (1982) formalism and the methodology described in Briole et al. (1986).

The data from GPS campaigns and the RS2 interferogram encompass the entire sequence and cannot constrain each single event. We first calculated a single fault model using the GPS data (Table 2) only. Constraining the fault azimuth and dip angles in the ranges $5-20^{\circ}$ and $60-80^{\circ}$, respectively, in accordance with the focal mechanism, and leaving all other parameters free, the data inversion led us to a unique solution independently of the initial conditions, thanks to the good coverage of GPS points in both azimuth and distance. Due to the fact that the residuals of the GPS points 15 and 14 were large, we ran a second inversion, excluding them. The best-fitting model was almost similar but $2 \mathrm{~km}$ less extended to the north end. The best-fitting fault azimuth and dip angles are $14^{\circ}$ and $70^{\circ}$. We kept those values fixed for the following inversions. The best-fitting depth of the upper edge of the fault is $2.5 \pm 0.5 \mathrm{~km}$. This depth is well constrained by the GPS points located at intermediate distances (e.g. ranging 10-20 km from the fault centre) as shallower depth lead to much larger displacements at those points. The best-fitting lower edge of the fault is less well constrained and in the range

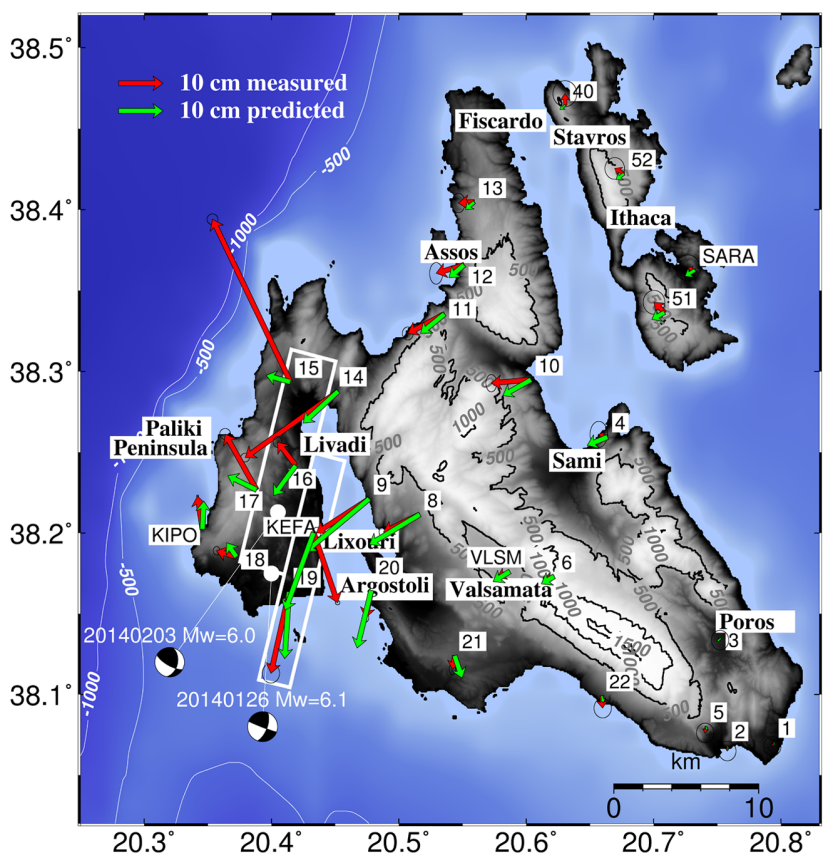

Figure 12. Best-fitting model for the entire sequence. Observed (green) and modelled (red) GPS vectors (values are in Table 2). The rectangles show the projection of the modelled fault, both dipping east, the main strike-slip fault is located deeper and south and the one located to the north is shallower with a lower dip angle. The focal mechanisms of both events are shown.

8-10 km, and this 1-fault inversion leads to an almost pure strikeslip movement on the fault.

This 1-fault model is however unable to fit the vertical motion at the GPS points located in the near range and it is unable to fit the observed RS2 fringes as well. To produce significant fringes and vertical displacements in Paliki, where the largest motions are observed, it is necessary to introduce a component of dislocation at shallow depth. We therefore added a second fault to our model. Initially aligned above the first one (as a narrow band located between 1 and $2.5 \mathrm{~km}$ depth), this shallow fault moved during the inversion process to a few kilometres toward north and rotated to a low dip angle of $30 \pm 5^{\circ}$, with a significant component of reverse faulting. We then ran several inversions changing the initial conditions (except the azimuth and dip angle of the first fault) and found a range of models that allowed us to estimate uncertainties on the fault parameters.

Finally, we took into account the results of the modelling of the February 3 earthquake (see next section) to slightly tune this model into a best-fitting model compatible also with the constraints on the February 3 earthquake. Table 5 gives the parameters and uncertainties of our final model for the entire sequence.

The average discrepancy between the $115 \mathrm{RS} 2$ picked values and the model is $23 \mathrm{~mm}$, and the average discrepancy between the observed and modelled GPS vectors is $16 \mathrm{~mm}$ in east, $23 \mathrm{~mm}$ in north and $20 \mathrm{~mm}$ in vertical. Table 2 gives the values of the observed and modelled GPS displacements and they are plotted in Fig. 12.

Table 5. Parameters of the best-fitting model for the entire sequence. The fit to the data is $20 \mathrm{~mm}$ for GPS and $26 \mathrm{~mm}$ for RS2. The centroid depth (average for the sequence) is $5.1 \mathrm{~km}$.

\begin{tabular}{|c|c|c|c|c|c|c|c|c|c|}
\hline Model & East $\left(^{\circ}\right)$ & North $\left(^{\circ}\right)$ & $\mathrm{Up}(\mathrm{km})$ & Length (km) & Width $(\mathrm{km})$ & $\operatorname{Dip}\left(^{\circ}\right)$ & Slip (m) & Rake $\left(^{\circ}\right)$ & Moment $\left(\times 10^{18} \mathrm{~N} \mathrm{~m}\right)$ \\
\hline Deep fault & $20.41 \pm 0.01$ & $38.18 \pm 0.01$ & $2.5 \pm 0.5$ & $16 \pm 2$ & $6.5 \pm 1$ & $70 \pm 5$ & $1.16 \pm 0.1$ & $173 \pm 5$ & 3.16 \\
\hline Shallow fault & $20.39 \pm 0.01$ & $38.25 \pm 0.01$ & $2.0 \pm 0.5$ & $15 \pm 2$ & $4.0 \pm 1$ & $30 \pm 5$ & $0.42 \pm 0.1$ & $145 \pm 5$ & 0.53 \\
\hline
\end{tabular}




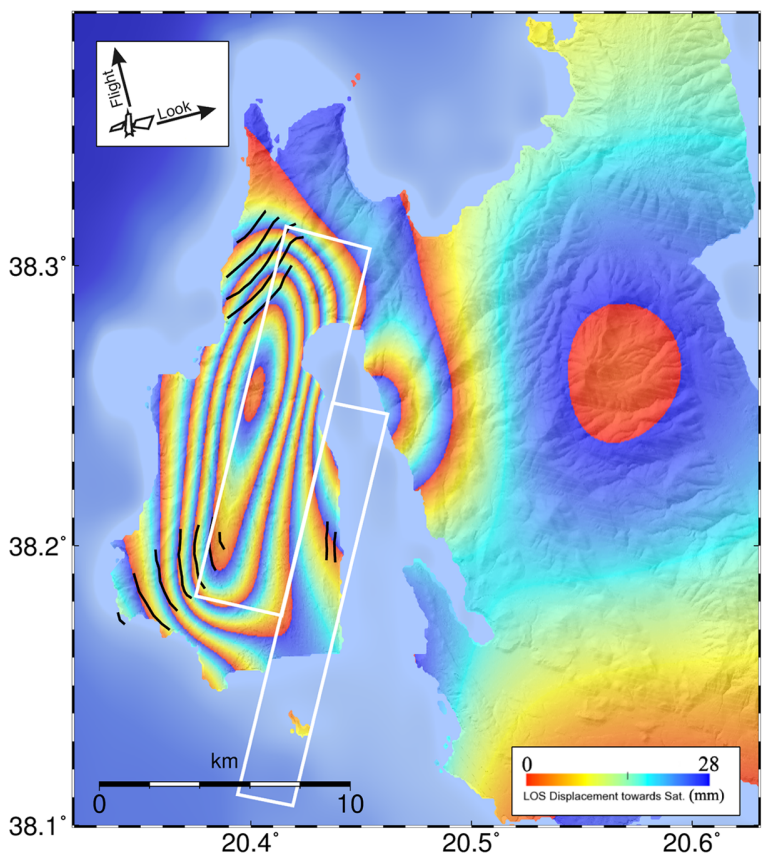

Figure 13. Best-fitting model for the entire sequence. Observed (picked fringes in black) and modelled RS2 interferogram. The rectangles show the projection of the modelled fault, both dipping east, the main strike-slip fault is located deeper and south and the one located to the north is shallower with a lower dip angle. The average scatter between RS2 observation and model is $26 \mathrm{~mm}$.

The picked fringes and the modelled interferogram are plotted in Fig. 13.

We are aware that our final model is simple compared to the more sophisticated models published by Sakkas \& Lagios (2015), but it is constrained in a robust manner by the various data sets, and the simplicity of the model allows smoothing the influence of the rheological and structural heterogeneities of the medium. To the opposite, variable slip models ran assuming a homogenous elastic half space will interpret any heterogeneity of the data as due to a variable slip which can be erroneous. We are not sure that for magnitude 6 earthquakes with fault length on the order of 10 $\mathrm{km}$, sophisticated model are generally justified and supported by data. On the other side, several works on larger crustal earthquakes (mostly strike slip) with magnitude 6.5 , or higher, have clearly shown the usefulness of variable slip models. It seems to us that in the case of the Cephalonia sequence, the quality of the data, the size of the earthquakes and the uncertainties on the rheology and structure, do not justify such refinement.

\section{MODELLING OF THE FEBRUARY 3 EARTHQUAK E}

We used 330 TSX and 330 CSK (re-sampling the original 920) observations picked from the readable fringes (as described in Section 4) for the February 3 source model. We used the same number of

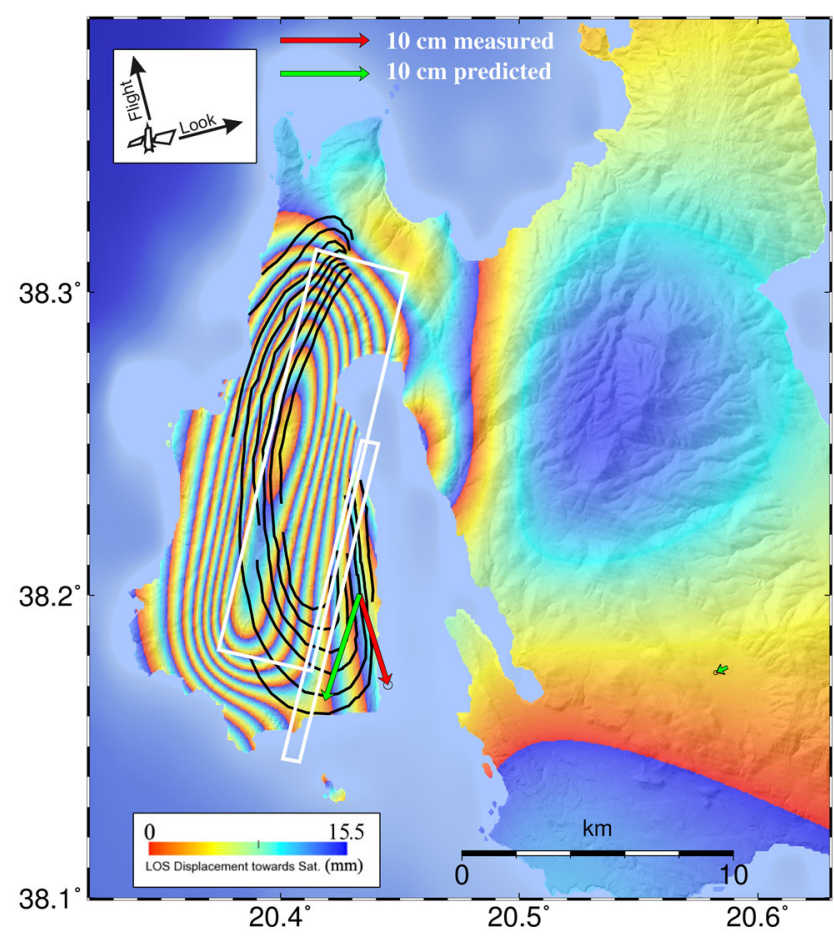

Figure 14. Best-fitting model for the February 3 earthquake. Observed (picked fringes in black) and modelled TSX interferogram. Observed and modelled displacements at KEFA and VLSM GPS stations. The rectangles show the location of the two elements of the modelled fault. The average scatter between observation and model is $26 \mathrm{~mm}$.

picking for the two interferograms so as to give same weights to both view angles.

As initial conditions, we used the geometry of the model estimated in the previous section for the entire sequence. This geometry appeared to be adapted the model of the February 3 earthquake, when leaving only part of the upper main fault slipping and the entire secondary shallow fault activated. The only parameter difficult to conciliate between both models was the rake angle on the shallow fault: in the case of modelling the entire sequence such angle was found close to $165^{\circ}$, while when modelling the February 3 event with no other constraints it was close to $115^{\circ}$. We then fixed rake value at $135^{\circ}$ and ran the rest of the inversion leaving free the other parameters. The initial fault azimuth of $14^{\circ}$ and the location of the main fault were not significantly modified by the inversion and the location of the shallow fault moved slightly $(3 \mathrm{~km})$ to the north to fit better the fringes patters there.

Finally our best model was the result of a slight tuning aimed at improving the consistency with the model for the entire sequence. Table 6 gives the parameters of the model and uncertainties and Figs 14 and 15 show the modelled interferograms together with the picked fringes. The average residual is $26 \mathrm{~mm}$ for TSX and 41 $\mathrm{mm}$ for CSK (and 23 when the fringes above the fault and near its end termination are not used). The quality of the fit with the GPS observations at VLSM and KEFA is a further validation of this model (Figs 14 and 15, and values in Table 2).

Table 6. Parameters of the best-fitting model for the earthquake of February 3 . The fit is $26 \mathrm{~mm}$ for TSX and $23 \mathrm{~mm}$ for CSK data. The centroid depth is $3.2 \mathrm{~km}$.

\begin{tabular}{lccccccccc}
\hline Model & East $\left({ }^{\circ}\right)$ & North $\left({ }^{\circ}\right)$ & Up $(\mathrm{km})$ & Length $(\mathrm{km})$ & Width $(\mathrm{km})$ & Dip $\left({ }^{\circ}\right)$ & Slip $(\mathrm{m})$ & Rake $\left({ }^{\circ}\right)$ & Moment $\left(\times 10^{18} \mathrm{~N} \mathrm{~m}\right)$ \\
\hline Deep fault & $20.42 \pm 0.01$ & $38.20 \pm 0.01$ & $2.5 \pm 0.5$ & $12 \pm 2$ & $1.8 \pm 1$ & $70 \pm 5$ & $1.16 \pm 0.1$ & $173 \pm 5$ & 0.60 \\
Shallow fault & $20.39 \pm 0.01$ & $38.25 \pm 0.01$ & $2.0 \pm 0.5$ & $15 \pm 2$ & $4.0 \pm 01$ & $30 \pm 5$ & $0.42 \pm 0.1$ & $145 \pm 5$ & 0.53 \\
\hline
\end{tabular}




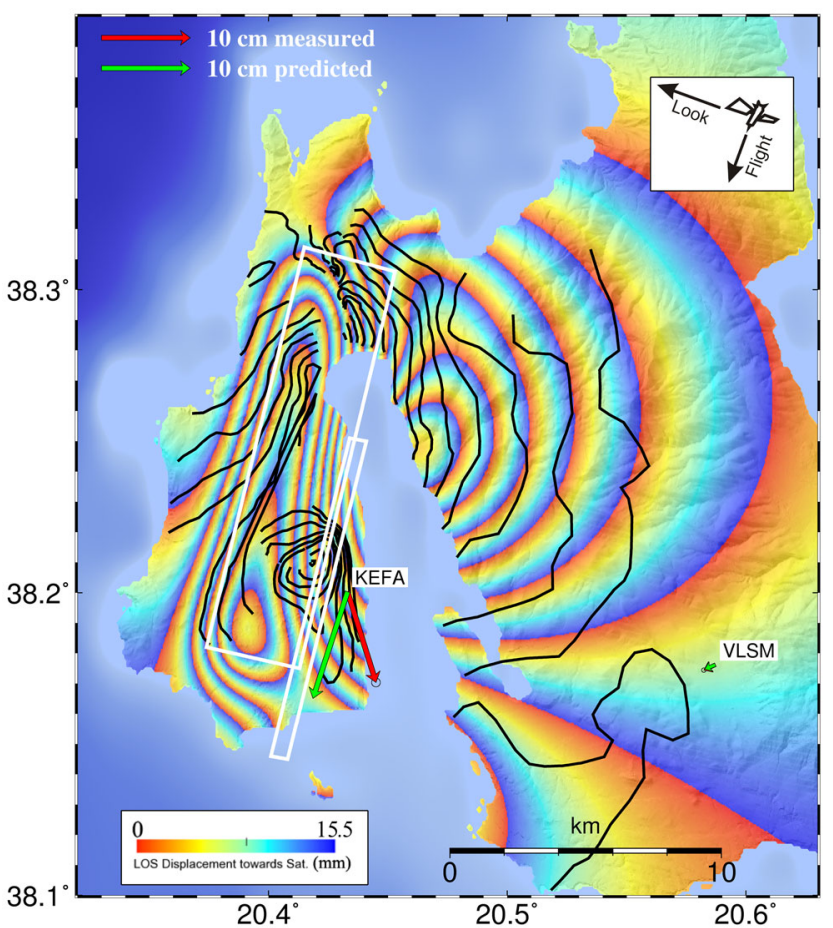

Figure 15. Best-fitting model for the February 3 earthquake. Observed (picked fringes in black) and modelled CSK interferogram. Observed and modelled displacements at KEFA and VLSM GPS stations. The rectangles show the location of the two elements of the modelled fault. The average scatter between observation and model is $41 \mathrm{~mm}$ when all data are considered and $23 \mathrm{~mm}$ when removing the pickings located above the faults trace.

The model for the February 3 event suggests that the rupture started as a strike-slip event along the upper tip of the rupture of January 26 (the two thirds located to the north) at depths ranging between 2.5 and $\sim 4.5 \mathrm{~km}$, and then continued with a shallower rupture on a low angle fault with oblique reverse slip (rake $135^{\circ}$ ). This scenario is compatible with the focal mechanism proposed for that earthquake and may explain the range of solutions found for that focal mechanism. The centroid depth according to our model is $3.2 \mathrm{~km}$, and the seismic moment inferred from the geodetic data $1.13 \times 10^{18} \mathrm{~N} \mathrm{~m}$. The fault length from the southern end of the fault to the north of the shallow secondary fault is $\sim 20 \mathrm{~km}$, which is compatible with the observed duration of the source.

Our model is unable to fit the numerous and narrow fringes observed north of Paliki (around GPS point 15) and in the centre south of Paliki, near its east coast. The deformations in those two areas can probably not be modelled using simple planar faults and the hypothesis of elasticity, as the shallow crust is certainly not elastic and not homogenous (Trasatti et al. 2011), with the possibility of inelastic deformation and folding of the shallow geological structures. We found nowhere in the interferograms, evidence of a fault segment reaching the surface. In such case the fringes would merge completely which is not the case. This is compatible with the fact that the rupture trace has not been observed in the field (Nikolaou et al. 2014; Valkaniotis et al. 2014).

\section{CONCLUSIONS}

Thanks to the good spatial coverage of our picked fringes and the existence of fringes sufficiently distant from the fault, especially for CSK, and thanks to the availability of both ascending

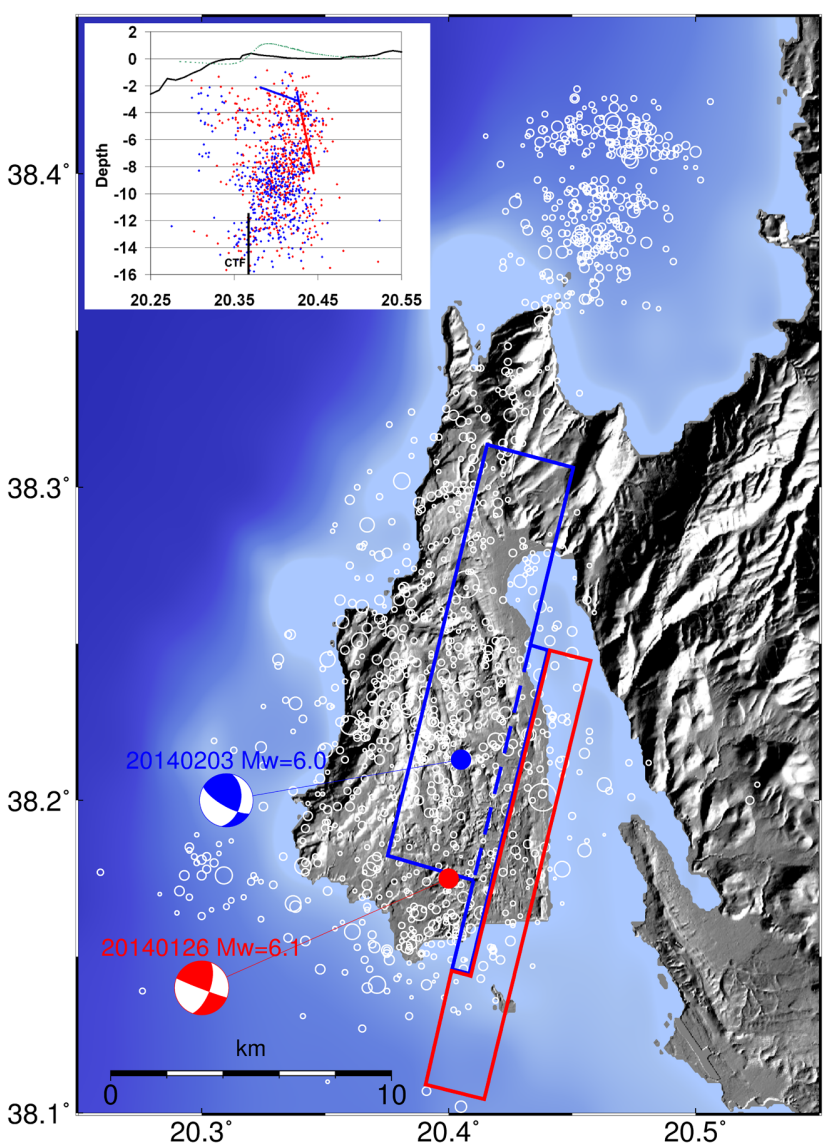

Figure 16. Projection of the faults inferred for the January 26 earthquake (red) and the February 3 earthquake (blue) with the seismicity relocated between January 26 and February 18 by Karakostas et al. (2015) and the CGMT focal mechanisms. The fault of the February 3 event has two elements, one coplanar with the January 26 fault and the other one with low angle. The direction of slip is shown with the thick arrows. The figure in inset shows a cross section along a $\mathrm{N} 102^{\circ}$ direction $\left(\mathrm{A}-\mathrm{A}^{\prime}\right.$ section) with in red and blue the location of the faults, in hatched black the location of the CTF as inferred from the interseismic GPS data, in solid black the topography, and in dotted green the vertical displacement that would be produced by $10^{4}$ events similar to the one we have estimated for the 2014 sequence. Most of the aftershock sequence occurs in the longitude domain located between the CTF and the 2014 faults.

and descending data, and GPS vectors, our inversions leaded to robust faults parameters and uncertainties. This was done with the simple hypothesis of elastic homogenous medium and uniform slip. It would be interesting to produce models using a more realistic structure and rheology, especially for the uppermost crust. We think that variable slips models have relatively little interest if not using an accurate model of structure, especially for such shallow and relatively small events affecting areas with a complex geology.

Using first the data encompassing the whole sequence and then the data sampling the February 3 earthquake only, we found a robust scenario for the sequence and for the two main events separately (Fig. 16), fitting all data sets within $22 \mathrm{~mm}$ average discrepancy, a value consistent with the uncertainties of the geodetic data.

The January 26 earthquake occurred beneath the south of Paliki on a $16-\mathrm{km}$-long fault, with azimuth $14^{\circ}$, dipping $70^{\circ}$ east and at a depth ranging from 4 to $8.5 \mathrm{~km}$. We find a centroid depth of 6.4 $\mathrm{km}$ for that earthquake, in good agreement with the one estimated 


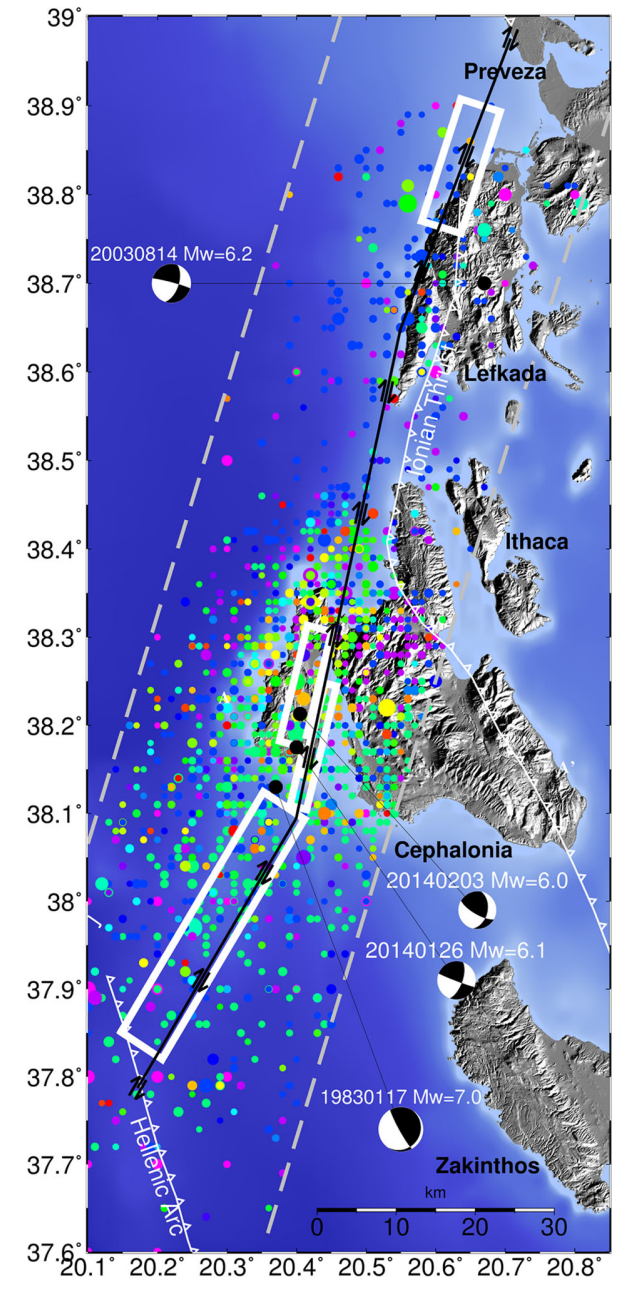

Figure 17. Spatio-temporal evolution of the seismicity (from the NOA catalogue) from 1980 to 2015 along the CTF. The two hatched white lines delimitate the area (40 km wide) for which we map the seismicity. The events shown are those with magnitude larger that 3.5 and shallower than 20 $\mathrm{km}$. The 1983 sequence is located immediately south of the 2014 one, with some overlap. The rectangles represent the location of the faults, deduced from this paper for 2014, from Ilieva (2011) for 2003, and from the G-CMT and the source parameters of Kiratzi \& Langston (1991) for 1983 (parameters in Table 7). The G-CMT focal mechanisms of the main shocks of 2014 January 26 and February 3, 2003 August 14 as well as of 1983 January 17 are plotted. We plotted in black the location of the CTF where we argue it could be according to our study.

from the seismological data. Our estimated seismic moment for the global fault is $3.69 \pm 0.410^{18} \mathrm{~N} \mathrm{~m}$, while the sum of the G-CMT moments is $3.57 \times 10^{18} \mathrm{~N} \mathrm{~m}$. To calculate the geodetic moment: we used rigidities of $21 \mathrm{GPa}(0-4 \mathrm{~km}$ depth) and $27 \mathrm{GPa}$ (4-8 km depth), thus 10-20 per cent less that what is used usually for modelling crustal earthquake, to account for the shallow locations of those events. The location, azimuth and dip angle of our inferred fault is consistent with that proposed by Sakkas and Lagios (2015) as well as the overall centroid depth and moment.

The February 3 earthquake occurred partly on the same fault as that of January 26, but at shallower depth, between 2.5 and $4 \mathrm{~km}$, and partly on a low dip angle $\left(30^{\circ}\right)$ shallow fault with a significant amount of reverse slip (rake $135^{\circ}$ ). This presence of reverse faulting is also proposed by Merryman Boncori et al. (2015) although with a different geometry for the faults segments. The centroid depth of the event, combining the contributions of the two faults is 3.2

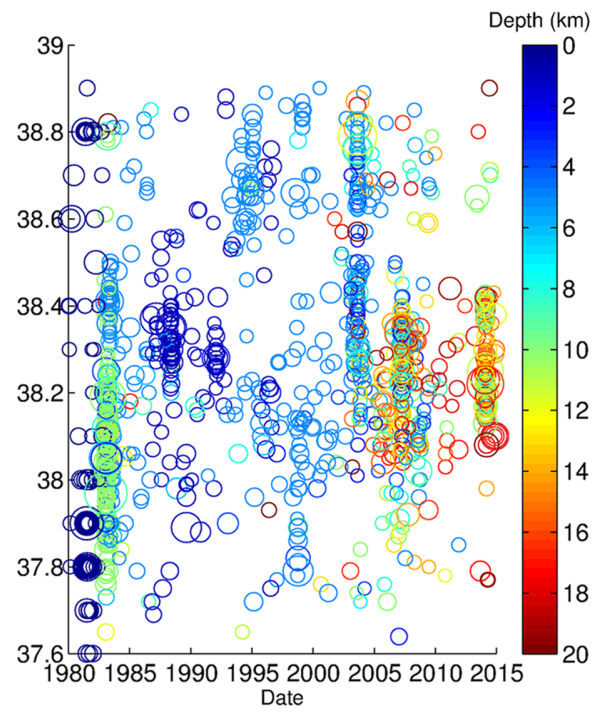

Figure 18. Spatio-temporal evolution of the seismicity (from the NOA catalogue) from 1980 to 2015 along the CTF, plotted with latitude function of date. The events are those located between the two hatched white lines of Fig. 17, with magnitude larger than 3.5 and shallower than $20 \mathrm{~km}$. The clustering in time and space of the seismicity is clear, as well as the gap of seismicity between Cephalonia and Lefkada. The 2003 sequence has two patches. The northern one is well correlated with the observed ground deformations (from GPS and SAR interferometry). The southern one, with little or no related deformation, is less understood.

$\mathrm{km}$, a value compatible with that found by seismology. The complexity of the faulting, with the two different faults, might explain the variability of the solutions proposed for the focal mechanism by several studies. The length of the overall faulting for that earthquake is $20 \mathrm{~km}$, thus more than that of the first event, and this relatively large length is consistent with the relatively long duration of the source as inferred from seismology. The February 3 earthquake may have affected only the pre-Apulian series and the uppermost young and soft series while the January 26 earthquake appears to have broken rocks at larger depth. Repeated earthquakes on the same fault should produce a signature in the topography that seems to exist (inset of Fig. 16) but is small and needs to be better investigated.

Our model for the entire sequence does not require dislocation below a depth of 8-9 $\mathrm{km}$ a value in good agreement with the range of possible locking depth deduced from the analysis of the interseismic GPS. The simplicity of the elastic modelling, neglecting the effects of heterogeneities and plasticity of the shallow crust, does not allow fitting all the details of the observed deformation field, especially with faults rupturing at shallow depths. The westward limit of the fault is well constrained by our model and consistent with the fact that the coseismic motion of KIPO is towards north, thus this points located west of the fault. The occurrence of those two large earthquakes beneath Paliki, rather than west of the peninsula, suggests that an eastern branch of the CTF was activated during the 2014 sequence, located approximately $7 \mathrm{~km}$ east of the main axis of the CTF, this main axis being located beneath the eastern coast of the island as consistently inferred from interseismic GPS (this study), geology and geomorphology. The inset of Fig. 16 shows that most of the aftershock sequence occurs in the area delimited by the CTF to the west and the January 26 fault to the east. The shallower February 3 earthquake may have occurred partly on a ramp bridging at shallow depth the two strike slip structures. The Paliki peninsula is located near the centre of the transition zone of the CTF, and 
Table 7. Parameters of the faults plotted in Fig. 17. From Ilieva (2011) for the $M_{\mathrm{w}}=6.22003$ August 14 earthquake. Averaging the G-CMT and the solution of Kiratzi \& Langston (1991) for the $M_{\mathrm{S}}=7.01983$ January 17 earthquake, and assuming a fault length of $35 \mathrm{~km}$.

\begin{tabular}{lccccccccc}
\hline Event & East $\left({ }^{\circ}\right)$ & North $\left({ }^{\circ}\right)$ & Up $(\mathrm{km})$ & Length $(\mathrm{km})$ & Width $(\mathrm{km})$ & Dip $\left({ }^{\circ}\right)$ & Slip $(\mathrm{m})$ & Rake $\left({ }^{\circ}\right)$ & Moment $\left(\times 10^{18} \mathrm{~N} \mathrm{~m}\right)$ \\
\hline $17 / 1 / 83$ & 20.33 & 37.94 & & 35 & 15 & 45 & 1.10 & 165 & 15 \\
$14 / 8 / 03$ & 20.63 & 38.83 & 6.8 & 16 & 10 & 59 & 0.75 & 180 & 3.6 \\
\hline
\end{tabular}

therefore partly dragged north with the Apulian platform, with an amount of shear of $6-7 \mathrm{~mm} \mathrm{yr}^{-1}$ to be accommodated off shore to the west according to the overall balance of GPS velocities in the broad area.

The 2014 sequence is located immediately north of the 1983 sequence and south of the rupture area of the 2003 Lefkada earthquake (Figs 17 and 18, Table 7; Benetatos et al. 2005; Karakostas \& Papadimitriou 2010), the southern end of which is still debated, with authors placing it immediately south of Lefkada (latitude $\sim 38.6^{\circ}$ ) and others proposing a secondary break off northwest Cephalonia based on the observed aftershocks and displacements of GPS points there. The seismic moment of the 2003 earthquake is however not compatible with a fault length of $40 \mathrm{~km}$ and agrees better with the $22 \mathrm{~km}$ extension of the aftershocks (Karakostas \& Papadimitriou 2010) or the $16 \mathrm{~km}$ found by Ilieva (2011) from the modelling of SAR interferometry data. During the January-February 2014 sequence, aftershocks were observed again off the northwest Cephalonia, west of Assos, but with no significant dislocation inferred from SAR interferometry and from the nearby campaign GPS points. The analysis of the interseismic GPS data from this area suggests a greater locking depth than the one we have found for the centre of Paliki. With its low level of seismicity recorded since 1980, the status of this intermediate area, between the two segments that broke in 2003 and 2014, needs to be clarified. The possibility of a strong earthquake, filling this gap, cannot be ruled out. A single event, rupturing $20-40 \mathrm{~km}$ of gap, would have a magnitude between 6 and 7, in the same range as those of 1983, 2003 and 2014. To the south the large earthquake of 1983 may have broken most of the CTF between Cephalonia (i.e. the southern end of the 2014 January 26 fault) and the junction with the subduction. The azimuth of this southern segment, as defined by the available focal mechanisms, the location of the seismicity and marine seismic studies, is $30-40^{\circ}$ which differs significantly from the value $10-20^{\circ}$ found beneath Paliki for the 2014 sequence and earlier events. The elbow between the two segments of the CTF would be situated immediately south of Paliki, at the junction between the 1983 and 2014 earthquakes, the south part of the CTF having also lower dip angles. This variation in the azimuth of the CTF is also compatible with the $0.05 \mu$ strain $\mathrm{yr}^{-1}$ shortening measured by GPS throughout Cephalonia.

\section{ACKNOWLEDGEMENTS}

We thank DLR (Deutsches Zentrum für Luft- und Raumfahrt), ASI (Agenzia Spaziale Italiana), CSA (Canadian Space Agency) and ESA (European Space Agency) for their help for obtaining images and facilitating the quick scheduling of new acquisitions after the first earthquake, the Hellenic Cadastrial Service for providing the $5 \mathrm{~m}$ spatial resolution DEM used for producing the interferograms and V. Karakostas for sending us his relocated seismicity. We are grateful to the three reviewers and the editor who made many useful comments and suggestions.

\section{REFERENCES}

Aubouin, J. \& Dercourt, J., 1962. Zone préapulienne, zone ionienne et zone du Gavrovo en Péloponnèse occidental, Bulletin de la Société Géologique de France, 4, 785-794.

Benetatos, C., Kiratzi, A., Roumelioti, Z., Stavrakakis, G., Drakatos, G. \& Latoussakis, I., 2005. The 14 August 2003 Lefkada Island (Greece) earthquake: focal mechanism of the mainshock and of the aftershock sequence, J. Seismol., 9, 171-190.

Briole, P., De Natale, G., Gaulon, R., Pingue, F. \& Scarpa, R., 1986. Inversion of geodetic data and seismicity associated with the Friuli earthquake sequence (1976-1977), Ann. Geophys., 4(B4), 481-492.

Clement, C., Hirn, A., Charvis, P., Sachpazi, M. \& Marnelis, F., 2000. Seismic structure and the active Hellenic subduction in the Ionian islands, Tectonophysics, 329, 141-156.

Costantini, M., 1998. A novel phase unwrapping method based on network programming, IEEE Trans. Geosci. Remote, 36, 813-821.

EPPO/ITSAK, 2014. Strong ground motion of the February 3, 2014 (M6.0) Cephalonia Earthquake: effects on soil and built environment in combination with the January 26, 2014 (M6.1) event, EPPO/ITSAK technical report.

Floyd, M.A. et al., 2010. A new velocity field for Greece: implications for the kinematics and dynamics of the Aegean, J. geophys. Res., 15(B10), doi:10.1029/2009JB007040.

Ganas, A., Marinou, A., Anastasiou, D., Paradissis, D., Papazissi, K., Tzavaras, P. \& Drakatos, G., 2013. GPS-derived estimates of crustal deformation in the central and north Ionian Sea, Greece: 3-yr results from NOANET continuous network data, J. Geodyn., 67, 62-71.

Goldstein, R. \& Werner, C., 1998. Radar interferogram filtering for geophysical applications, Geophys. Res. Lett., 25, 4035-4038.

Hatzfeld, D., Kassaras, I., Panagiotopoulos, D., Amorese, D., Makropoulos, K., Karakaisis, G. \& Coutant, O., 1995. Microseismicity and strain patters in northwestern Greece, Tectonics, 14(4), 773-785.

Ilieva, M., 2011. Crustal deformations of shallow earthquakes in the Eastern Mediterranean studied by radar interferometry and seismology, $P h D$ thesis, UPMC-Paris VI, France and NIGGG-BAS, Sofia, Bulgaria, $179 \mathrm{pp}$.

Karakostas, V. \& Papadimitriou, E., 2010. Fault complexity associated with the 14 August $2003 M_{\mathrm{W}} 6.2$ Lefkada, Greece, aftershock sequence, Acta Geophys., 58(5), 838-854.

Karakostas, V., Papadimitriou, E., Mesimeri, M., Gkarlaouni, C. \& Paradisopoulou, P., 2015. The 2014 Kefalonia doublet $\left(M_{w} 6.1\right.$ and $\left.M_{w} 6.0\right)$, Central Ionian Islands, Greece: seismotectonic implications along the Kefalonia transform fault zone, Acta Geophys., 63(1), doi:10.2478/s11600014-0227-4.

Kiratzi, A.A. \& Langston, C.A., 1991. Moment tensor inversion of the 1983 January 17 Kefallinia event of Ionian islands (Greece), Geophys. J. Int., 105(2), 529-535.

Kokinou, E., Papadimitriou, E., Karakostas, V., Kamberis, E. \& Vallianatos, F., 2006. The Kefalonia Transform Zone (offshore Western Greece) with special emphasis to its prolongation towards the Ionian Abyssal Plain, Mar. geophys. Res., 27, 241-252.

Lagios, E., Papadimitriou, P., Novali, F., Sakkas, V., Fumagalli, A., Vlachou, K. \& Del Conte, S., 2012. Combined seismicity pattern analysis, DGPS and PSInSAR studies in the broader area of Cephalonia (Greece), Tectonophysics, 524-525, 43-58.

Le Pichon, X., Chamot-Rooke, N., Lallemand, S., Noomen, R. \& Veis, G., 1995. Geodetic determination of the kinematics of Central Greece with respect to Europe: implications for Eastern Mediterranean tectonics, $J$. geophys. Res., 100(12), 675-690. 
Lekkas, E., Danamos, G. \& Maurikas, G., 2001. Geological structure and evolution of Cefallonia and Ithaki Islands, Bull. Geol. Soc. Greece, 34(1), $11-17$.

Louvari, E., Kiratzi, A. \& Papazachos, B.C., 1999. The Cephalonia Transform Fault and its extension to western Lefkada Island (Greece), Tectonophysics, 308, 223-236.

Merryman Boncori, J.P. et al., 2015. The February 2014 Cephalonia earthquake (Greece): 3D deformation field and source modeling from multiple SAR techniques, Seismol. Res. Lett., 86(1), 1-14.

Müller, M.D.M., 2011. Analysis of long-term GPS observations in Greece (1993-2009) and geodynamic implications for the Eastern Mediterranean, $P h D$ dissertation $n^{\circ} 19796$, ETH, Zurich.

Nikolaou, A. et al., 2014. GEER/ERRI/ATC Earthquake Reconnaissance January $26^{\text {th }} /$ February $2^{\text {nd }} 2014$ Cephalonia, Greece Events, version 1: 2014 June 6.

Okada, Y., 1985. Surface deformation due to shear and tensile faults in a half-space, Bull. seism. Soc. Am., 75(4), 1135-1154.

Papadimitriou, E.E., 1993. Focal mechanism along the convex side of the Hellenic Arc and its tectonic significance, Boll. Geof. Teor. App., 35, 401-426.

Papadimitriou, E.E., 2002. Mode of strong earthquake recurrence in the central Ionian Islands (Greece): possible triggering due to Coulomb stress changes generated by the occurrence of previous strong shocks, Bull. seism. Soc. Am., 92(8), 3293-3308.

Papagiannopoulos, G.A., Hatzigeorgiou, G.D. \& Beskos, D.E., 2012. An assessment of seismic hazard and risk in the islands of Cephalonia and Ithaca, Greece, Soil Dyn. Earthq. Eng., 32(1), 15-25.

Papoulia, J. et al., 2014. A new seismogenic model for the Kyparissiakos Gulf and western Peloponnese (SW Hellenic Arc), Bollettino Di Geofisica Teorica Ed Applicata, 55(2), 405-432.

Pérouse, E., Chamot-Rooke, N., Rabaute, A., Briole, P., Jouanne, F., Georgiev, I. \& Dimitrov, D., 2012. Bridging onshore and offshore presentday kinematics of central and eastern Mediterranean: implications for crustal dynamics and mantle flow, Geochem. Geophys. Geosyst., 13(9), doi:10.1029/2012GC004289.

Sachpazi, M. et al., 2000. Western Hellenic subduction and Cephalonia Transform: local earthquakes and plate transport and strain, Tectonophysics, 319(4), 301-319.
Sakkas, V. \& Lagios, E., 2015. Fault modelling of the early-2014 M6 Earthquakes in Cephalonia Island (W. Greece) based on GPS measurements, Tectonophysics, 644-645, 184-196.

Scordilis, E.M., Karakaisis, G.F., Karakostas, B.G., Panagiotopoulos, D.G., Comninakis, P.E. \& Papazachos, B.C., 1985. Evidence for transform faulting in the Ionian sea - the Cephalonia island earthquake sequence of 1983, Pure appl. Geophys., 123(3), 388-397.

Shaw, B. \& Jackson, J., 2010. Earthquake mechanisms and active tectonics of the Hellenic subduction zone, Geophys. J. Int., 181(2), 966984.

Sorel, D., 1989. L'évolution structurale de la Grèce nord-occidentale depuis le Miocène, dans le cadre géodynamique de l'arc Egéen, Thèse d'Etat, Univ. of Paris XI-Orsay, France, 475 pp.

Stiros, S.C., Pirazzoli, P.A., Laborel, J. \& Laborel-Deguen, F., 1994. The 1953 Earthquake in Cephalonia (Western Hellenic Arc): coastal uplift and halotectonic faulting, Geophys. J. Int., 117, 834-849.

Tarantola, A. \& Valette, B., 1982. Generalized nonlinear inverse problems solved using the least square criterion, Rev. Geophys Space Phys, 20(2), 219-232.

Trasatti, E, Kyriakopoulos, C. \& Chini, M., 2011. Finite element inversion of DInSAR data from the Mw 6.3 L'Aquila earthquake, 2009 (Italy), Geophys. Res. Lett., 38, L08306, doi:10.1029/2011GL046714.

Tselentis, G.-A., Melis, N.S., Sokos, E. \& Beltas, P., 1997. The winter 1991-1992 earthquake sequence at Cephalonia island, western Greece, Pure appl. Geophys., 150, 75-89.

Valkaniotis, S., Ganas, A., Papathanassiou, G. \& Papanikolaou, M., 2014. Field observations of geological effects triggered by the January-February 2014 Cephalonia (Ionian Sea, Greece) earthquakes, Tectonophysics, 630, $150-157$.

Ventura, B.M., Serpelloni, E., Argnani, A., Bonforte, A., Bürgmann, R., Anzidei, M., Baldi, P. \& Puglisi, G., 2014. Fast geodetic strain-rates in eastern Sicily (southern Italy): new insights into block tectonics and seismic potential in the area of the great 1693 earthquake, Earth planet. Sci. Lett., 404, 77-88.

Wegmuller, U. \& Werner, C., 1997. Gamma SAR processor and interferometry software, in Proceedings of the the 3rd ERS Symposium on Space at the Service of Our Environment, Florence, Italy, 1997 March 14-21, European Space Agency, p. 1687. 